\title{
Sobre a práxis da Análise do Discurso da Sociologia do Conhecimento
}

\author{
[Doing research with the Sociology of Knowledge Approach to Discourse] \\ http://dx.doi.org/10.11606/1982-88372444475
}

\section{Reiner Keller ${ }^{1}$ \\ Tradução de Daniel Martineschen ${ }^{2}$}

\begin{abstract}
This article introduces the sociology of knowledge approach to discourse (SKAD). This approach to social science discourse research has been widely received in the German-speaking world and for some time now also internationally. SKAD combines the analysis of power/knowledge regimes called for by Foucault with the interpretative paradigm of sociology, in particular with the pragmatist tradition of symbolic interactionism and the social constructivist sociology of knowledge. To this end, important basic concepts and, in particular, proposals for the methodology and implementation of corresponding discourse studies are presented.
\end{abstract}

Keywords: Power/knowledge; Discourse; Dispositive; Sociology of knowledge; Interactionism; Actors; Data analysis.

Resumo: Este artigo é uma introdução à Análise do Discurso da Sociologia do Conhecimento (ADSC). Trata-se de uma abordagem da pesquisa discursiva dentro das ciências sociais que goza de antiga recepção no espaço de língua alemã e recentemente também em âmbito internacional. Essa abordagem combina a análise de regimes de saber/poder postulada por Foucault com o paradigma interpretativo da sociologia, em especial com a tradição pragmática do interacionismo simbólico e da sociologia do conhecimento social-construtivista. São apresentados importantes conceitos fundamentais, além de sugestões para a metodologia e a aplicação metódica de estudos discursivos correspondentes.

Palavras-chave: Saber/poder; Discurso; Dispositivo; Sociologia do conhecimento; Interacionismo; Atores; Análise de dados.

Zusammenfassung: Der Beitrag führt in die Wissenssoziologische Diskursanalyse (WDA) ein. Dabei handelt es sich um einen seit langem im deutschsprachigen Raum und inzwischen auch international breit rezipierten Ansatz der sozialwissenschaftlichen Diskursforschung. Dieser Ansatz verbindet die von Foucault geforderte Analyse von Macht/Wissen-Regimen mit dem

\footnotetext{
${ }^{1}$ Universität Augsburg, Philosophisch-Sozialwissenschaftliche Fakultät, Universitätsstraße 10, D-86159 Augsburg, Alemanha. E-mail: reiner.keller@phil.uni-augsburg.de. ORCID: 0000-0002-6083-0458

${ }^{2}$ Universidade Federal de Santa Catarina, Departamento de Língua e Literatura Estrangeiras, Campus Universitário Trindade, S/N, Florianópolis, SC, 88040-900, Brasil. E-mail: martineschen@ gmail.com. ORCID: 0000-0002-2909-1861.

Publicado originalmente em: KelLER, Reiner. Zur Praxis der Wissenssoziologischen Diskursanalyse. In: Keller, Reiner; TruschKat, Inga (Hrsg.). Methodologie und Praxis der Wissenssoziologischen Diskursanalyse. Band 1: Interdisziplinäre Perspektiven. Wiesbaden: Springer VS, 2012, p. 27-68.
}

Revisão técnica da tradução: Simone Pereira Gonçalves e Poliana Coeli Costa Arantes.

\section{BY-NC}

Pandaemonium, São Paulo, v. 24, n. 44, set.-dez. 2021, p. 475-518 
KELLER, R. - Sobre a práxis da Análise do Discurso da Sociologia do Conhecimento

Interpretativen Paradigma der Soziologie, insbesondere mit der pragmatistischen Tradition des Symbolischen Interaktionismus und der sozialkonstruktivistischen Wissenssoziologie. Dazu werden wichtige Grundbegriffe und insbesondere Vorschläge zur Methodologie und methodischen Umsetzung entsprechender Diskursstudien vorgestellt.

Stichwörter: Macht/Wissen; Diskurs; Dispositiv; Wissenssoziologie; Interaktionismus; Akteure; Datenanalyse.

A "Análise do Discurso da Sociologia do Conhecimento" [Wissenssoziologische Diskursanalyse (ADSC) $^{*}$ descreve um programa de pesquisa nas Ciências Sociais destinado à análise de relações e políticas de saber sociais (KELLER 1998, 2001, 2003a, 2005a, 2011, 2013, 2019, KELLER; HoRNIDGE \& SCHÜNEMANN 2018). A importância e a factualidade de realidades físicas e sociais são instituídas pelos atores sociais, no uso da linguagem e dos símbolos, dentro e por meio de discursos. A ADSC trata de examinar tais processos da construção social de estruturas interpretativas e de ação (regimes de saber, políticas de saber) no nível de instituições, organizações ou de atores coletivos, como também trata de investigar os efeitos sociais desses processos. Podemos entender os discursos como esforços estruturados e estruturantes de criar e estabilizar significados - ou, de maneira mais geral, ordens simbólicas de extensão mais ou menos ampla - e, portanto, de institucionalizar um contexto vinculativo, ou seja, uma ordem de saberes para campos práticos específicos em coletivos sociais. Essa construção discursiva da realidade constitui um corte (eminentemente importante) daquilo que Peter Berger e Thomas Luckmann (1980 [1966]) denominaram a "construção social da realidade". 3 A ADSC tem como suas bases a Análise do Discurso dentro da Sociologia do Conhecimento de Berger e Luckmann, a tradição do Interacionismo Simbólico e a tradição do enfoque dado por Foucault aos regimes de poder/saber, e visa analisar os discursos não como sistema processador semiótico distanciado da realidade, mas sim como práxis social.

O conceito de "relações sociais de saber" foi baseado no conceito de "relações de definição" formulado por Ulrich Beck, considerando os conflitos e discursos de risco que, por sua vez, alude a Karl Marx ou às "relações de produção". Relações sociais de saber

\footnotetext{
* A tradução da denominação desta área de conhecimento (ainda bastante inédita em português) representa um desafio à parte, pois é necessário manter tanto o componente da Análise do Discurso (Diskursanalyse) quanto da Sociologia do Conhecimento (em alemão, no adjetivo wissenssoziologisch), mesmo que isso signifique o risco da cacofonia com a profusão de preposições "de". "Análise discursiva" não parece apontar para a já consolidada área da $\mathrm{AD}$, portanto não seria uma opção. Optamos portanto por "Análise do Discurso da Sociologia do Conhecimento", e talvez o que venha a se consolidar, para além do nome extenso, seja a abreviação ADSC [N. T.].

3 Outras dimensões construtivas podem ser diferenciadas da construção discursiva: "construção comunicativa" (KELLER; KNOBLAUCH \& REICHERTZ 2012) designa uma categoria mais geral (a construção discursiva é uma forma de construção comunicativa).
}

Pandaemonium, São Paulo, v. 24, n. 44, set.-dez. 2021, p. 475-518 
KELLER, R. - Sobre a práxis da Análise do Discurso da Sociologia do Conhecimento

são as configurações das afirmações da realidade, isto é, da factualidade e normatividade criadas socialmente e situadas historicamente, e que expandem o horizonte local, nacional, transnacional e global daquilo que é tido como "realidade social". Isso inclui, além daquilo que é factual, verdadeiro e correto, também definições do belo, do possível, do bem e do mal, do sobrenatural, transcendental etc. Tais relações de saber aparecem quase como uma "realidade objetiva". Contudo, assim como as relações de produção, elas são um produto externalizado da atividade humana e socializada; dessa forma, elas estruturam interpretações e condutas na medida em que são 'realizadas' por atores sociais em atividades de tradução correspondentes. E elas podem ser modificadas pela práxis humana, social, por acontecimentos e problematizações. Assim, o conceito de relações sociais de saber compreende aquilo que Michel Foucault entende como regimes de poder/saber. Trata-se de políticas de saber para registrar duas coisas: em primeiro lugar, o caráter processual e transitório das relações de saber (trata-se sempre de constelações temporárias e relativamente estáveis); em segundo, o papel ativo dos atores sociais que, no âmbito das problematizações e dos processamentos de acontecimentos, estão envolvidos com a produção e com a alteração de relações de saber. É por isso que políticas de saber não são nem limitadas ao espaço - normalmente suspeito - do político, nem reduzidas apenas às disputas por desenvolvimentos (tecnológicos) arriscados. As políticas de saber acontecem, antes, nos mais diversos campos de ação sociais; elas são a expressão do caráter conflituoso e controverso da construção social da realidade.

A Análise do Discurso da Sociologia do Conhecimento se insere nas tradições social-construtivistas e interpretativas da Sociologia do Conhecimento, e contribuiu para que, recentemente, as tradições interpretativas se debruçassem cada vez mais sobre os meso-níveis (das organizações e atores coletivos) e os macroníveis (de processos de mudança estruturais e institucionais) do saber. ${ }^{4}$ Ela se orienta por aquilo que, na tradição de Berger e Luckmann, é entendido como "realidade objetiva" [objektive Wirklichkeit] como sendo o lado da sociedade. A ADSC utiliza simultaneamente os elementos simbólico-interacionistas, social-fenomenológicos e pragmáticos que ali são recuperados: o uso social de símbolos em discursos pressupõe sistemas de símbolos, competências de uso e também contextos de problemas ou relevâncias pragmáticas. Apesar de justamente a tradição pragmático-interpretativa ter cunhado muito cedo o conceito de universo

\footnotetext{
${ }^{4}$ Cf. por exemplo os trabalhos em Keller, Hornidge \& Schünemann (2018) bem como as indicações em Keller (2012), Keller, Knoblauch \& Reichertz (2012) e também Clarke (2005).
}

Pandaemonium, São Paulo, v. 24, n. 44, set.-dez. 2021, p. 475-518 
KELLER, R. - Sobre a práxis da Análise do Discurso da Sociologia do Conhecimento

discursivo [Diskursuniversum] e utilizado o mesmo como sistemas de signos socialmente criados, estabilizados e modificados e, portanto, como ordenamentos de sentidos realizados; e apesar de ser possível rastrear aqui uma experiência relativamente longa na análise de "Vocabulários de Motivos" sociais e orientados à situação (Charles W. Mills) e de "definições situacionais" conflituosas (William I. Thomas \& Dorothy Thomas) apesar disso, não se desenvolveu aqui nenhuma perspectiva discursiva das ciências sociais em sentido estrito. Por isso, a ADSC remete a considerações foucaultianas sobre o funcionamento de discursos e dispositivos e à sua aplicação em 'lutas sociais', e constrói sua argumentação ao longo das afinidades com a tradição interpretativa ali existentes. A ADSC se conecta explicitamente com uma demanda de Stuart Hall (1997), cuja concepção do conceito de discurso, totalmente acentuada na Sociologia do Conhecimento, foi incorporada apenas de maneira restrita nos Estudos Culturais Britânicos. A análise de relações e políticas de saber, da forma exposta acima, também mostra afinidades com recentes discussões no contexto de perspectivas pós-coloniais e decoloniais, bem como com as respectivas questões relativas a relações e políticas de saber entre o 'norte global' e o 'sul global'. Tudo isso está exposto em outro texto e não será repetido aqui. ${ }^{5}$ Em vez disso, no que se segue vamos contemplar sobretudo questões referentes à implementação prática da ADSC.

\section{Um programa de pesquisa e sua aplicação necessariamente seletiva}

A ADSC foi concebida propositalmente de maneira ampla e, se contemplarmos a partir da referência a discursos, dispositivos e saberes, bastante independente do objeto analisado. Isso se destaca nos textos já mencionados não apenas nos conceitos propostos, mas também nos possíveis questionamentos ali discutidos a respeito das pesquisas sobre discurso. Para ela, trata-se de reavivar potenciais de análise de sociologia do conhecimento subutilizados e pouco aproveitados nas últimas décadas. A sua elaboração se nutre a partir de vários impulsos. Entre eles estão sobretudo a ampliação dos objetos de análise acessíveis por meio de estratégias de pesquisa interpretativas das ciências sociais, em especial aquelas da sociologia. Além disso, tem-se a impressão de que as

\footnotetext{
${ }^{5} \mathrm{Cf}$. sobre isso as referências apontadas no início do texto.
} 
KELLER, R. - Sobre a práxis da Análise do Discurso da Sociologia do Conhecimento

pesquisas do discurso de fundamentação linguística, com seu impressionante repertório metodológico e metódico, estão mais interessadas em outras questões (na mudança linguística e conceitual; em estruturas linguísticas ou gramaticais etc.), e elas até conseguem deduzir mudanças e estruturas linguísticas com seus próprios meios tradicionais de análise de grandes corpora, contudo não conseguem alcançar os processos sociais e práxis discursivas da construção de realidades, incluindo os objetos, as ações e as dimensões de significado e de conhecimento da linguagem relacionadas. No campo da pesquisa sócio-científica acerca do discurso acrescenta-se a impressão de um instrumental bastante específico da Análise Crítica do Discurso direcionada à crítica da ideologia e do uso da linguagem, instrumental esse que se adéqua apenas parcialmente à complexidade das relações e políticas de saber. E, de maneira muito semelhante, a análise da hegemonia de Ernesto Laclau e Chantal Mouffe, orientada a questionamentos de teoria da hegemonia e à análise de mobilizações políticas, constrói uma compreensão de discurso precisa, mas mesmo assim muito reduzida e inclusive com carga psicanalítica. Por fim, muitas das Análises de Discurso "foucaultianas" são relativamente intransparentes com relação à sua metodologia e aos seus métodos. ${ }^{6}$

O próprio Foucault considerava que suas reflexões sobre a análise de formações discursivas eram incompletas, provisórias e concebidas com muitos problemas e questões em aberto, e empreendeu diferentes modos de aplicação do conceito de discurso que compreendem desde a análise de formações discursivas até a lida com batalhas discursivas (cf. KELLER 2008). Por isso, na ADSC tratava-se e trata-se de apresentar um procedimento teoricamente fundado e empiricamente gerenciável para a pesquisa sociológica acerca do discurso que tenha em si poucas premissas teóricas a respeito dos objetos. Assim, de fato a ADSC esboça uma heurística e uma analítica dos discursos com base teórico-metodológica, mas não formula mecanismos de explicação causal nem premissas a respeito daquilo que sempre parece estar em ação em processos discursivos concretos. Antes, ela persegue a ideia weberiana do entrelaçamento entre compreensão e esclarecimento: é a análise da práxis social, de fundamentos, processos e consequências de discursos ou conflitos discursivos que pode dar informações sobre quais podem ser enunciados relevantes para cada caso específico. Nesse sentido, enquanto discurso sobre discursos, ela disponibiliza saber contextualizado e análises contextualizadas que não são

\footnotetext{
${ }^{6} \mathrm{Cf}$. mais detalhes sobre isso em Keller (2019). Sobre o grau de difusão do uso do conceito de discurso em várias pesquisas empíricas, cf. por exemplo Leipold (2014).
}

Pandaemonium, São Paulo, v. 24, n. 44, set.-dez. 2021, p. 475-518 
KELLER, R. - Sobre a práxis da Análise do Discurso da Sociologia do Conhecimento

determinadas por um construto teórico (com base em teoria marxista, social ou semiológica). ${ }^{7}$ Por isso, toda análise real no âmbito da ADSC necessita de tradução e adaptação específicas para o objeto. Ou seja, a ADSC não determina um procedimento padrão à Análise do Discurso. No entanto, é claro que oferece algumas sugestões sobre como lidar concretamente com a concepção e a aplicação de pesquisas discursivas orientadas pela análise do saber (KELLER 2003a).

Com base em Foucault e outros, a ADSC compreende os discursos como práticas enunciativas reguladas, surgidas e contextualizadas historicamente e que constituem os objetos dos quais tratam. Essa definição retirada da "Arqueologia do saber" de Foucault teve diversas variações, mas ela ainda assim constitui o cerne que norteia a pesquisa sociológica do discurso. O próprio Foucault incorporou diferentes pontos de vista sobre os discursos, enfatizando ora as construções estruturais emergentes, ora as disputas entre os discursos. No contexto francês da sua época era perceptível uma significativa influência da sociologia de Émile Durkheim, mesmo que isso não se expresse de maneira explícita. Responsável por isso é, por um lado, a tradição estruturalista: Ferdinand de Saussure desenvolvera sua teoria linguística com base na concepção sociológica de instituições e estruturas de Émile Durkheim, e Claude Lévi-Strauss aprimorou esta concepção com base no estruturalismo e na antropologia universal. Mas por outro lado, Foucault dá ao estruturalismo uma nova virada histórico-empírica, que por sua vez é influenciada por Durkheim. A obra tardia de Durkheim na sociologia do conhecimento esboça uma sociologia histórica das concepções coletivas (representações) que também compreende o tempo e o espaço como categorias sociais. Por isso, a denominação da cadeira de Foucault no Collége de France, "História dos sistemas de pensamento", pode ser lida como uma reformulação dos conceitos durkheimianos. Seu olhar sobre as formações discursivas, que nesse sentido é influenciado mais implícita que explicitamente pela tradição de Durkheim, apresenta muitas afinidades com a perspectiva institucional - também fortemente baseada em Durkheim - da "construção social da realidade". No entanto, a tradição interpretativa da sociologia demonstrou suficientemente que as estruturações institucionais não agem simplesmente como fios aos quais os atores sociais estão presos como "marionetes atuantes", mas sim que se trata de regras e recursos de interpretação e ação. Tais regras e recursos certamente advêm, por um lado, de longos encadeamentos de ações, apresentando portanto efeitos de emergência

\footnotetext{
${ }^{7}$ Isso não exclui nem referências a conceitos teóricos atuais nem “efeitos críticos” (cf. KELLER 2016).
} 
KELLER, R. - Sobre a práxis da Análise do Discurso da Sociologia do Conhecimento

e efeitos colaterais das atividades humanas. Por outro lado, contudo, exigem apropriações socializadoras e representações práticas e performativas. Isso quer dizer que são aplicadas no contexto de processos de interpretação e ação relativamente criativos. Elas não determinam as problematizações sociais, mas as instruem, disponibilizando estruturações de restrições e possibilidades.

Enquanto Foucault originalmente se concentrava em primeiro lugar em discursos científicos e em seus jogos de verdade, a ADSC leva em consideração também discursos públicos ou discursos de tópicos ou eventos específicos e debates discursivos em arenas sociais parciais. Para este último, pode-se supor uma estruturação difusa das posições do falante, bem como misturas híbridas e heterogêneas dos elementos do enunciado, que por sua vez são obtidos de origens muito diferentes, e, a seguir, vinculados uns aos outros em uma combinação específica. No centro da análise estão inicialmente os discursos e os conflitos de definição estruturados discursivamente, nos quais estão sempre envolvidos atores institucionais ou organizacionais e coletivos e, claro, os indivíduos. Isso certamente inclui também práticas em contextos organizacionais, como mudanças no ensino e nos estudos que podem ser sentidas nas atividades cotidianas das universidades após as reformas educacionais. O nível da fala privada cotidiana e dos processos cotidianos de significação que acontecem "na esfera reprodutiva" também não são entendidos como “discurso". O próprio Foucault reservou o termo de discurso para "atos de fala sérios", não para os altos e baixos das microconversas cotidianas. Quando trocamos algumas frases no bar, nos cumprimentamos e perguntamos: “Como vai?”, reclamamos que o ônibus partiu ou que o gato está doente, ou do barulho insuportável e da última noite de bebedeira, quando nos aproximamos de pessoas com palavras amigáveis etc., todas essas são práticas linguísticas no sentido da compreensão inglesa do discurso como cotidiano e interações linguísticas (conforme são então examinados na “discourse analysis" de língua inglesa ou na pesquisa de conversação alemã). Mas, no sentido da terminologia de Foucault, estes não são atos de fala institucionalizados e serializados que são condensados em formações discursivas - embora tais práticas de linguagem cotidiana sejam naturalmente permeadas por figuras interpretativas e blocos de construção de formações discursivas, e a questão da extensão em que os elementos discursivos permeiam a interpretação e a ação cotidiana possa se aproximar dos limites da Análise do Discurso da Sociologia do Conhecimento -, desde perguntas sobre nutrição saudável, passando pela discussão de questões de educação, até chegar à sexualidade vivida etc. Por último, 
KELLER, R. - Sobre a práxis da Análise do Discurso da Sociologia do Conhecimento

mas não menos importante, essas práticas cotidianas de linguagem podem ser os lugares onde surgem novas estruturas discursivas de fatos.

Além dessa delimitação, uma extensão também deve ser observada. O foco de análise da ADSC aponta não apenas ou exclusivamente para as questões da formação histórica do "sujeito moderno" ao longo de sua corporeidade, sua razão, sua sexualidade, sua governabilidade, como salientou Michel Foucault (1983, 2000 [1984]), para si mesmo. Pelo contrário: a ADSC inclui toda a amplitude dos objetos sociologicamente acessíveis. Isso inclui também conflitos sobre a demarcação de limites entre natureza e sociedade, sobre a definição de riscos, sobre cenários de desenvolvimento social futuro etc.

Com base na longa tradição da pesquisa social interpretativa, e também da consideração dos desenvolvimentos recentes da sociologia da ciência e da tecnologia (no interacionismo simbólico, nos Social Studies of Science ou na teoria ator-rede), ela enfatiza mais ainda a importância das práticas, materialidades e dos dispositivos na análise. Certamente o foco está nos enunciados como elementos básicos da estruturação discursiva. No entanto, inúmeras outras práticas de apoio ou "fazeres" ["doings"] (como a coleta e visualização de dados processados estatisticamente) pertencem à prática discursiva de enunciar; além disso, há o que se pode compreender no termo "materialidades", ou seja, todas as coisas que fluem para a produção de enunciados ou dela resultam como efeitos de intervenção no mundo. Resumi as grandezas correspondentes sob o conceito de dispositivo. Dispositivos são, por um lado, as infraestruturas de produção do discurso, isto é, o tecido de práticas discursivas e não discursivas, coisas, pessoas, regulações, que possibilitam e acompanham a produção de enunciados que formam um discurso. Contudo, dispositivos são também os aparatos ou as infraestruturas de intervenção no mundo resultantes de um discurso ou de constelações discursivas mais ou menos conflituosas. Nesse sentido, a Análise do Discurso da Sociologia do Conhecimento é muito mais do que análise de texto; ela inclui como possibilidade etnografias de discurso focado (KELLER 2003b) que se relacionam com a análise dos dispositivos correspondentes, e usa todo o espectro de procedimentos de estudos de caso de ciências sociais quando se trata de abordar a complexidade das formações discursivas e seus "efeitos no mundo". Isso inclui abordagens históricogenealógicas, estudos comparativos síncronos, bem como a incorporação em questões de ciências sociais mais abrangentes e interesses de análise. 
KELLER, R. - Sobre a práxis da Análise do Discurso da Sociologia do Conhecimento

Ao mesmo tempo, a ADSC enfatiza as limitações da pesquisa do discurso: o social e o discursivo não são idênticos. A pesquisa sobre o discurso na sociologia do conhecimento oferece um olhar orientado especificamente de maneira teórica, metodológica e metódica sobre processos da construção (justamente) discursiva, além de outras abordagens sociológicas possíveis e legítimas. Os processos de discurso que ela vislumbra constituem o que pode ser considerado como "problematizações históricas" e "modo de lidar com acontecimentos". Ela pressupõe que existem "discursos" assim como existem "famílias" - pois "família" também é apenas um conceito tipificador para constelações empiricamente muito heterogêneas de pessoas, átomos, moléculas... (e como discursos têm que ser "feitos", as famílias também têm que ser "feitas" - e isso pode ter aparências muito diversas). Ao mesmo tempo, não se pode presumir que as demandas, implicações e projetos que surgem nas arenas discursivas sejam implementados um a um nos processos de intervenção ou formação no mundo - para além disso, a complexidade real das constelações discursivas, efeitos da inércia institucional e "situações" do mundo (CLARKE 2005), é alta demais. Os discursos também produzem efeitos intencionais e não intencionais - tornar isso claro talvez seja um dos usos mais importantes da pesquisa empírica do discurso.

O vocabulário de análise da ADSC foi apresentado em detalhes em outros textos (Keller 2003a, 2005a, 2013, 2019, Keller; HoRnidge \& SchÜnEMANN 2018). As sugestões feitas neles certamente permitem trabalhar um amplo espectro de questões e áreas temáticas, e - além dos fundamentos teóricos básicos - dispensam pressupostos teoricamente determinantes sobre o processamento empírico dos discursos - na verdade, este último é justamente tratado como o "real" interesse da pesquisa do discurso.

\section{$2 \bigcirc$ fator humano}

A título de exemplo, gostaria aqui de explicar alguns conceitos de análise adicionais que dizem respeito às variadas e muito diferentes manifestações do "fator humano" nos discursos (cf. KELLER 2012). Uma investigação empírico-analítica dos discursos na perspectiva da Análise do Discurso da Sociologia do Conhecimento diferencia:

- atores sociais (individuais ou coletivos) socialmente constituídos que suscitam questões sociais em suas atividades e atuam (temporariamente) como locutores ou destinatários de discursos;

Pandaemonium, São Paulo, v. 24, n. 44, set.-dez. 2021, p. 475-518 
KELLER, R. - Sobre a práxis da Análise do Discurso da Sociologia do Conhecimento

- as posições do locutor fornecidas nos discursos;

- outros envolvidos na produção do discurso e intervenção no mundo, empregados nos dispositivos de um discurso;

- as posições subjetivas mantidas à disposição em discursos;

- os métodos concretos de subjetivação com os quais os atores sociais como destinatários se apropriam das posições de sujeito mantidas (parcial e teimosamente). à disposição

A ADSC distingue as posições do sujeito apresentadas no discurso das práticas reais de interpretação de ação dos atores cotidianos envolvidos em experiências e situações complexas. Ela vê as correspondências "um a um" como algo concebível mas que na prática ocorre apenas muito raramente. Em contraste, presume-se a possibilidade de formação de sujeito ou modos de subjetivação de ocorrência sócio-histórica muito diferentes, cuja forma real é uma questão empírica. A obstinação operativa da interpretação e ação humanas, a "posicionalidade excêntrica" (Helmuth Plessner) do ser humano, alterna entre a invocação discursiva e seu efeito subjetivante. $\mathrm{Na}$ abordagem da Sociologia do Conhecimento Hermenêutica de matriz social-construtivista, desenvolvida por Hans-Georg Soeffner, Ronald Hitzler, Jo Reichertz, Norber Schröer e Hubert Knoblauch e na tradição do paradigma interpretativo ao qual se reporta a ADSC, os atores humanos são determinados de duas maneiras:

"como um sujeito autorreflexivo que interpreta e examina, diferencia ou resume os repositórios de saber sociais na apropriação cotidiana, (...) [e ao mesmo tempo] como destinatário dos repositórios de saber e das valorações neles embutidos." (HITZLER; REICHERTZ \& SCHRÖER 1999b: 13) ${ }^{8}$

Na Sociologia Hermenêutica do Conhecimento pressupõe-se que o horizonte da realidade dos atores é pré-estruturado historicamente por repositórios de saber da sociedade e por estruturas institucionais. A este respeito, não se aplica a objeção da "filosofia do sujeito" que às vezes é levantada com referência à rejeição de Foucault a algumas posições filosóficas fenomenológicas e hermenêuticas (por exemplo, FOUCAULT 1974: 15) (ela é levantada, por exemplo, por ANGERMÜLLER 2005: 30ss.; e é igualmente inaplicável: MATTISEK; GLASZE 2009). Se a Sociologia Hermenêutica do Conhecimento e, de forma mais geral, a pesquisa social interpretativa indicam que os atores sociais agem de maneira orientada para o sentido ou com referência a estruturações de sentido, isso de

\footnotetext{
${ }^{8}$ Cf. também Soeffner (2004) e Hitzler, Reichertz \& Schröer (1999a).
} 
KELLER, R. - Sobre a práxis da Análise do Discurso da Sociologia do Conhecimento

forma alguma indica sua origem primordial na consciência individual e não implica necessariamente a questão de desempenhos ou conteúdos de consciência. Certamente, contudo, afirma-se que o processo de constituição do sentido só pode ocorrer na consciência individual. Se, por exemplo, um ator assume a posição de locutor em um discurso sociológico e se submete às regras desse discurso específico (ou seja, ao que pode ser dito e a como se pode dizê-lo), então isso só pode ocorrer como uma prática na medida em que tal locutor empreenda as constituições de sentido correspondentes que foi capaz de realizar graças a uma socialização específica na formação discursiva. No entanto, essa socialização determina o que aparece como um enunciado tão pouco quanto o faz no uso comum da linguagem; no máximo, aumenta as probabilidades de "enunciados específicos"; mas a complexidade das situações e dos processos de resolução de problemas também atua como um catalisador para "inovações". Um catalisador permite a liberação de algo que já existe de certa forma, mas sem ser eficaz. Chamemos esta descoberta de campos de ação da criatividade.

A sociologia compreensiva como uma ciência da realidade visa compreender e explicar todas as construções humanas: tanto os produtos da atividade humana, as formas de socialização e as formas econômicas quanto as figuras de interpretação e visões de mundo. Parte do pressuposto de que a percepção e ação humana são limitadas por signos e que todas as construções sociais se resumem em "formas simbólicas" (Cassirer); de que nos movemos como intérpretes em um mundo interpretado por humanos; de que estamos emaranhados em nossos próprios símbolos e ficções ou construções da realidade; e de que temos que contar com a realidade ou eficácia real dessas ficções e construções na orientação de nossas ações (SOEFFNER 1999: 39ss.).

Esta dupla relação humana com o mundo implica processos de socialização, por exemplo, em formações discursivas, mas também em grupos sociais, organizações e campos de ação, nos quais são adquiridas (e superadas) as competências necessárias para interpretar e agir. Inclui também uma extensa rede de posições e interações recíprocas por meio das quais a unidade dos atores é constituída, estabilizada ou alterada ao longo do tempo, incluindo a fixação e a transformação de suas opções de ação possíveis e proibidas. Enquanto Foucault enfatiza que os sujeitos e as práticas são constituídos fundamentalmente por ações discursivas e regimes de saber emergentes, por sua vez a sociologia hermenêutica do saber aponta para a indispensabilidade do pressuposto de atores sócio-historicamente constituídos e relativamente individualizados (sociais). Esses atores se encontram numa disputa com problemas de interpretação e ação, bem como com as regras institucionais ou discursivas e com os recursos a eles disponíveis, que permitem e limitam sua interpretação e ação ao mesmo tempo. A disputa frequentemente resulta 
KELLER, R. - Sobre a práxis da Análise do Discurso da Sociologia do Conhecimento

numa grande "aplicação de conformidade com as regras", mas não se esgota nisso. Pelo contrário, é ao mesmo tempo o lugar onde o trabalho contingente de interpretação, criatividade, fantasia, imaginação e desejos entram em jogo. As manifestações do "fator humano" diferenciadas na listagem acima serão examinadas em mais detalhes adiante.

\section{Atores sociais}

A abordagem teórico-discursiva da Análise do Discurso da Sociologia do Conhecimento afirma que a definição de Foucault dos discursos como práticas requer um conceito de ator diferenciado. A ADSC trata de atores, locutores, posições do locutor, posições de sujeito e subjetivizações reais ou modos de subjetivação. Individuais e coletivos, mas em ambos os casos sempre atores sociais e constituídos por meio de uma quantidade de "processos de formação" (com relação a atores individuais, por exemplo: maturidade biológica, desenvolvimentos, diversas formas de socialização, de aquisição de competências no uso de signos, de orientação por regras e demais recursos de ação), eles tomam as regras e os recursos de produção da interpretação disponíveis na forma de discursos ou reagem a eles como destinatários, dentro de suas respectivas práticas discursivas atuais e específicas. Conectam-se ou desligam-se temporariamente dos discursos como locutores, na medida em que o permitam as condições do discurso, a arena, a problematização especificamente interessante. Só então é possível entender a forma como tais práticas surgem de maneira mais ou menos criativa: "As estruturas agem por meio de empreendimentos humanos." (SAHLINS 1992a: 118). As teorias da práxis não podem abrir mão da noção de autoridade para ação, ou seja, de atores "aptos para a ação" que estão em condições de se apropriar das rotinas da ação, de realizá-las e modificá-las com base em definições situacionais a serem adotadas. A ADSC sustenta que atores sociais são capazes de preservar o campo de ação para definir significados no contexto dos meios sócio-historicamente disponíveis, e também de se relacionar criativamente com as experiências situacionais e expectativas institucionais do discurso nas quais estão imersos. Por meio das suas interpretações reflexivas e práticas das condições estruturais de situações (e discursos), eles também podem conduzir à sua transformação. Nada disso pode ser confundido - inclusive na Sociologia Hermenêutica do Conhecimento! - com a negociação estratégica e consciente ou com o controle das consequências das ações feito pelos autores e suas intenções. Obviamente, as ações realizadas de forma habitual ocorrem sob condições estruturais que não foram criadas ou são controladas por eles 
KELLER, R. - Sobre a práxis da Análise do Discurso da Sociologia do Conhecimento

mesmos, e também é óbvio que que a ação tem consequências intencionais e não intencionais, visíveis e invisíveis que, como efeitos estruturais, se tornam pré-condições discursivas para ações subsequentes. O repositório coletivo de saber é justamente um repositório de ordens simbólicas que não são pretendidas e mutuamente acordadas pela consciência individual. Ele designa, de maneira metafórica, um "produto" social surgido de incontáveis eventos históricos de interpretação e de ação e que também não pode ser remetido a um esboço coletivo. Manter a categoria de atores sociais e focar a pesquisa do discurso não apenas no exame das posições dos locutores e dos locutores em si é algo importante, entre outras coisas, porque existe apenas uma direção de busca para a questão de porquê posições específicas dos locutores às vezes não são ocupadas, ou de quem é parte dos excluídos de um discurso. Ela também permite estabelecer que os atores não surgem "do nada", 9 mas são "atores com uma história", ou que um tal ator (especialmente um ator coletivo) pode intervir ou aparecer em pontos diferentes dos discursos - tanto em diversas posições de locutor como também no nível do conteúdo e dos destinatários. A categoria do ator permite ver mais de perto a conexão entre essas diferentes posições e questionar os seus efeitos.

\section{Posições de locutores}

Na linguagem da ADSC, as posições do locutor discursivo são settings discursivos institucionais ou organizacionais e também são complexos de papéis associados Foucault já havia falado de papéis (e operações) (FouCAUlT 2001a: 872). Atores sociais são, portanto, locutores ou articuladores, "vozes" que assumem tais posições e, como parte de um dispositivo material da produção do discurso, formulam os enunciados que constituem um discurso. Na sociologia, a teimosia dos sujeitos colocados nas posições desempenha um papel subordinado ou é (apenas) um problema na medida em que pode ser determinante para o grau de distância, interpretação e performance do discurso efetivamente utilizado nos enunciados discursivos - se isso for considerado significativo. Aqui deve-se ter em vista uma importante diferença entre os discursos. Discursos sociais especiais (como religião, ciência, direito) são caracterizados pelo fato de terem gerado uma forte estrutura e hierarquização institucional das posições dos seus locutores no processo histórico. Locutores em potencial devem passar por uma carreira, por formação

\footnotetext{
${ }^{9}$ Aí reside um problema principal de todas as análises de discursos e subjetivações estritamente orientadas por metodologia etnográfica ou pela análise da conversação.
}

Pandaemonium, São Paulo, v. 24, n. 44, set.-dez. 2021, p. 475-518 
KELLER, R. - Sobre a práxis da Análise do Discurso da Sociologia do Conhecimento

e socialização adequados para adquirirem o direito de se expressarem dentro de tais discursos e nas posições de locutor neles disponíveis (com oportunidades de receber audição distribuídas de forma desigual). Em contraste, os discursos públicos ou discursos em arenas públicas se baseiam num cenário de locutores estruturado de maneira muito mais heterogênea. Nesse cenário, diferentes recursos e capitais (simbólicos) determinam a legitimidade dos locutores e as possibilidades de articulação.

Além disso, para a pesquisa do discurso na sociologia do conhecimento é importante dispensar a suposição antecipatória de que certos interesses e posições de poder previamente determináveis resultariam sempre em posições e efeitos assumidos nos discursos. O mesmo interesse permite diferentes expressões no discurso; o poder pode mudar sua forma no processo do discurso, e é tanto uma consequência das estruturações discursivas quanto também seu input. Analisar ambos de maneira independente protege, a princípio, contra o apelo à "hermenêutica da suspeita" (Paul Ricoeur) e ajuda a enxergar que os mesmos atores (podem) assumir posições de falante muito diferentes e fazer afirmações, e que os efeitos do saber e da realidade sobre aquilo que dizem estão fora do seu controle.

Envolvidos na produção do discurso e intervenção no mundo

Se olharmos para o nível dispositivo* dos discursos e seus efeitos de poder, podemos identificar outra forma de incluir atores sociais nos discursos que não se enquadra na categoria da posição de locutor. As posições de locutor são acompanhadas por inúmeras funções, por uma equipe adicional mais ou menos apoiadora na produção do discurso, e pela intervenção no mundo discursivo-dispositiva. Seria lamentável ignorar esses agentes dedicados dos discursos, considerando a visão das posições dos locutores. Exemplos de tais grupos de pessoas são servidores públicos administrativos do setor escolar, que coletam dados estatísticos sobre notas escolares e currículos educacionais para o discurso das ciências sociais, os didatas que projetam reformas educacionais e os artefatos necessários para isso (materiais de ensino, estruturas de espaço, uso de tecnologia) etc. É evidente que os discursos não podem prescindir dessa equipe, e às vezes - por exemplo, no caso dos mentores ambientais citados adiante - a fronteira com relação aos locutores

\footnotetext{
* Neste artigo, Keller utiliza o adjetivo "dispositivo" no sentido de "organizador" ou que "dispõe uma ordem" [N.T.].
}

Pandaemonium, São Paulo, v. 24, n. 44, set.-dez. 2021, p. 475-518 
KELLER, R. - Sobre a práxis da Análise do Discurso da Sociologia do Conhecimento

e às locutoras é certamente fluida. Quando produzem efeitos de poder, os discursos mobilizam em seus settings institucionais uma equipe que se integra a infraestruturas institucionais mais ou menos extensas e, por exemplo, a assessora, informa e controla. Isso pode ser evidenciado no contexto dos discursos ambientais. Uma práxis ambientalmente correta ou sustentável para descarte de resíduos (seja lá o que isso signifique e por mais improvável que seja) requer extenso aparato material: registros estatísticos, contêineres, balanças, rótulos de produtos e, claro, as "pessoas" correspondentes. O exemplo a seguir se dirige a "mentores ambientais", ou seja, um grupo de agentes que treina e supervisiona a prática de separação de resíduos:

Figura 1: "Separação do lixo no condomínio"

\begin{tabular}{|c|c|c|c|c|}
\hline \multicolumn{4}{|c|}{ Was gehört in welche Tonne? } & Altglas \\
\hline BLAU & $\begin{array}{l}\text { GELB } \\
\text { Wertstoffe }\end{array}$ & T. GRUN & Restmüill & \multirow{2}{*}{$\begin{array}{l}\text { Leere Flaschen und } \\
\text { Glaser gehören nicht in } \\
\text { die Gelbe Tonne! } \\
\text { Altglasbehalter befinden } \\
\text { sich ganz in der Nähe } \\
\text { eines jeden Wohnheims. }\end{array}$} \\
\hline \multirow{2}{*}{$\begin{array}{l}\text { Papier \& Pappe } \\
\text { bitte immer nur } \\
\text { volumen- } \\
\text { reduziert }\end{array}$} & Alles, was den & \multirow{3}{*}{$\begin{array}{l}\text { Bitte den Muill in } \\
\text { Papiertiuten } \\
\text { einwerfen, } \\
\text { keine Plastik- } \\
\text { tüten benutzen! }\end{array}$} & \multirow{2}{*}{$\begin{array}{l}\text { Speisereste usw. } \\
\text { unbedingt in }\end{array}$} & \\
\hline & \multirow{2}{*}{$\begin{array}{l}\text { Grünen } \\
\text { Punkt } \\
\text { trägt - außer } \\
\text { Papier \& Glas! } \\
\end{array}$} & & & Sperrmüll \\
\hline $\begin{array}{l}\text { reduziert } \\
\text { einwerfen! } \\
\text { - Briefumschläge } \\
\text { - Brötchentüten } \\
\text { - Eierkartons }\end{array}$ & & & \multirow{2}{*}{$\begin{array}{l}\text { verpacken! } \\
\text { - Asche (kaltl) } \\
\text { - Brot } \\
\text { - Fisch \& Fleisch } \\
\text {. Kondome }\end{array}$} & $\begin{array}{l}\text { Mobel, Matratzen, } \\
\text { Regale, Teppiche, Koffer } \\
\text { usw, konnen zu den am } \\
\text { Infoboard ausgehängten } \\
\text { Terminen ordentlich an } \\
\text { den Straß̧enrand gestellt } \\
\text { werden. }\end{array}$ \\
\hline Karteikarten & - Joghurtbecher & - Gartenabfälle & & Sondermült \\
\hline Kataloge & - Kronkorken & - Gemüseabfälle & - Monatsbinden & \\
\hline Klopapierrollen & - Kunststoff & - Kaffeesatz & - Pflaster & $\begin{array}{l}\text { Medikamente stehen in } \\
\text { einigen Wohnheimen }\end{array}$ \\
\hline $\begin{array}{l}\text { Muslischachteth } \\
\text { Pappkartons }\end{array}$ & - Müstibeutel & & - Rasierklingen & $\begin{array}{l}\text { Sammelbehälter bereit. } \\
\text { Farben, Lacke, Săuren, }\end{array}$ \\
\hline Pizzakartons & - Spraydosen & - Küchentücher & & $\begin{array}{l}\text { Lösungsmittel, Batterien, } \\
\text { Reinigungsmittel usw. }\end{array}$ \\
\hline Prospekte & - Styropor & - Salatblätter & - Staubbeutel & \\
\hline & - Verbundstoffe & $\begin{array}{l}\text { - Schnittblumen } \\
\text { - Teebeutel }\end{array}$ & $\begin{array}{l}\text { verschmutztes } \\
\text { Papier }\end{array}$ & \\
\hline & & & & \\
\hline \multicolumn{4}{|c|}{ Was gehört nicht in die Tonne? } & Elektroge \\
\hline \multirow{7}{*}{$\begin{array}{l}\text { - beschichtetes } \\
\text { Papier } \\
\text { - Monatsbinden } \\
\text { - Servietten } \\
\text { - Tampons } \\
\text { - Taschentücher } \\
\text { - verschmutztes } \\
\text { Papier } \\
\text { - Wattepads }\end{array}$} & \multirow{7}{*}{$\begin{array}{l}\text { Der Grüne Punkt } \\
\text { ist das Zeichen } \\
\text { für Recycling und } \\
\text { nicht für die } \\
\text { Gelbe Mülltonne. } \\
\text { Glasflaschen und } \\
\text { Pappkartons } \\
\text { gehören hier } \\
\text { nicht rein! }\end{array}$} & \multirow{7}{*}{$\begin{array}{l}\text { - Asche } \\
\text { - Brot } \\
\text { - Fisch } \\
\text { - Fleisch } \\
\text { - Käse } \\
\text { - Kohle } \\
\text { - Speisereste } \\
\text { - Wurst } \\
\text { - Zigaretten }\end{array}$} & \multirow{7}{*}{$\begin{array}{l}\text { Was irgendwie } \\
\text { wiederverwertet } \\
\text { werden kann, } \\
\text { gehört nicht in } \\
\text { den Restmull!! } \\
\text { Die Kosten der } \\
\text { Grauen Tonne } \\
\text { werden auf die } \\
\text { Miete umgelegt! }\end{array}$} & \\
\hline & & & & \\
\hline & & & & \\
\hline & & & & nelstelle \\
\hline & & & & erden \\
\hline & & & & \\
\hline & & & & $\begin{array}{l}\text { Infos: } \\
\text { Eure: }\end{array}$ \\
\hline
\end{tabular}

Fonte: Site da moradia estudantil em Bonn (www.ende17.stw-bonn.de/?page_id=22), acesso em $05 / 02 / 2010$. 
KELLER, R. - Sobre a práxis da Análise do Discurso da Sociologia do Conhecimento

O texto que acompanha essa figura é o seguinte:

Os mentores ambientais garantem que o condomínio permaneça mais ou menos ambientalmente correto e que o lixo seja devidamente separado. Seus mentores ambientais são A. e B.

Posições de sujeito

O posicionamento e o endereçamento de atores sociais em discursos na forma de posições de sujeito devem ser diferenciados de tais manifestações do fator humano. Neste contexto, “sujeito" é entendido como uma forma assumida de reflexão e controle da ação, ou seja, uma auto-relação assumida - desejada, rejeitada, elogiada, denunciada - do controle da ação reflexiva de atores sociais individuais (e, em casos raros, coletivos). Os discursos esboçam uma complexa cartografia do sujeito do campo do qual eles tratam. Em confrontos antagônicos, por exemplo, eles constituem ofertas de identificação para subjetivação - ou seja, posições de sujeito - ao longo dos contrastes entre um "Nós" positivamente carregado e o "outro opositor". Em constelações mais complexas desenvolvem-se extensas estruturas de atuantes como heróis e vilões, salvadores necessitados e seus cúmplices, de espectadores, causadores de problemas e responsáveis etc. Ao mesmo tempo, como numa prancheta, surgem sujeitos modelo conectados com as correspondentes tecnologias modelo de si e que são apresentados aos vários destinatários de um discurso como uma promessa, um "modelo" ou um exemplo de advertência. Vamos ilustrar isso a seguir também por meio de exemplos. O pano de fundo para isso é o meu estudo das discussões públicas sobre o valor das coisas perecíveis e sobre o reaproveitamento do lixo desde a década de 1960 (KELLER 1998).

Nos discursos da política ambiental da década de 1970, emergiram as figuras complementares (posições de sujeito) conhecidas e populares do cidadão antiecológico e do cidadão com consciência ecológica. Descrevi isso como "individualização e subpolitização da responsabilidade pelos resíduos” (ibid.). O jornal FAZ de 10/11/1971 publicou declarações de representantes do setor industrial da seguinte forma: "O único dano ambiental são as embalagens plásticas descartadas", e "o consumidor que joga lixo por tudo continua sendo o 'inimigo do meio ambiente"”. O jornal Die Welt cita o então ministro do Interior Hans Dietrich Genscher, que "dá um sermão aos cidadãos":

Devemos falar também do sofá rasgado que apodrece no bosque recreativo, do fogão enferrujado, do suporte torto para bicicletas, dos aterros clandestinos nas periferias. $\mathrm{O}$ 
KELLER, R. - Sobre a práxis da Análise do Discurso da Sociologia do Conhecimento

slogan é: "comportamento de consumo com consciência ambiental" (Die Welt, 15/01/1971).

Os sujeitos-modelo correspondentes ou as posições de sujeito modelo estão firmemente estabelecidos hoje, como mostram os exemplos a seguir. O "moleiro selvagem" ["wilde Müller"] * é um protótipo de poluição e destruição ambiental. Contrapõe-se a ele a imagem positiva do cidadão com consciência ambiental, que deve agir como sujeito com responsabilidade ambiental numa variedade de práticas de preservação do meio ambiente. No contexto francófono essa posição de sujeito é chamada de "Ecocitoyen" ["ecocidadão"]:

Figura 2: O moleiro selvagem

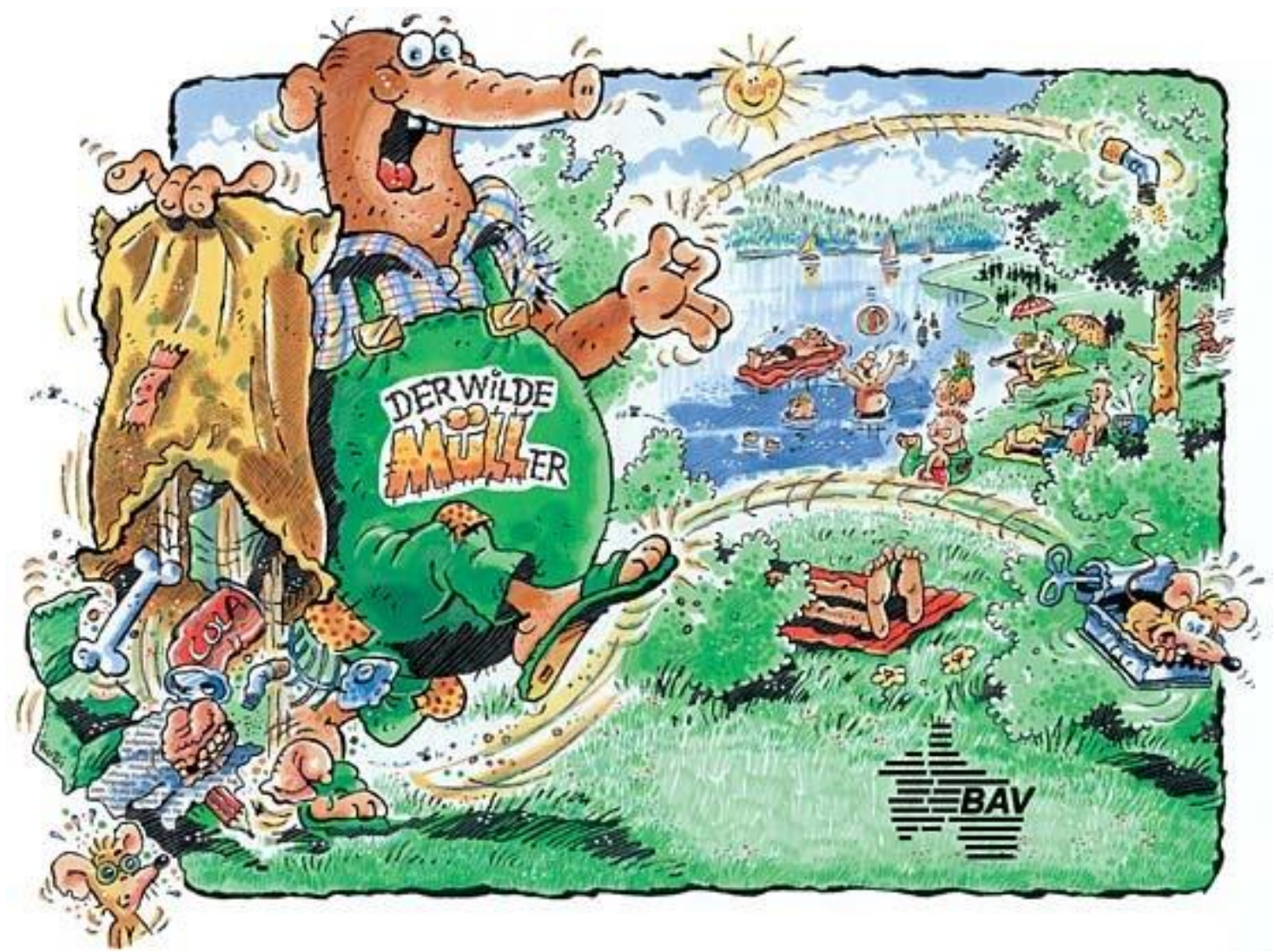

Fonte: site da Associação de Aproveitamento de Resíduos da Montanha (www.bavweb.de), acesso em 05/02/2010.

** Trocadilho com a palavra alemã "Müll”, que significa "lixo", e também com o sobrenome "Müller", tão comum na Alemanha quanto "Silva" no Brasil. [N. do T.] 
KELLER, R. - Sobre a práxis da Análise do Discurso da Sociologia do Conhecimento

Figura 3
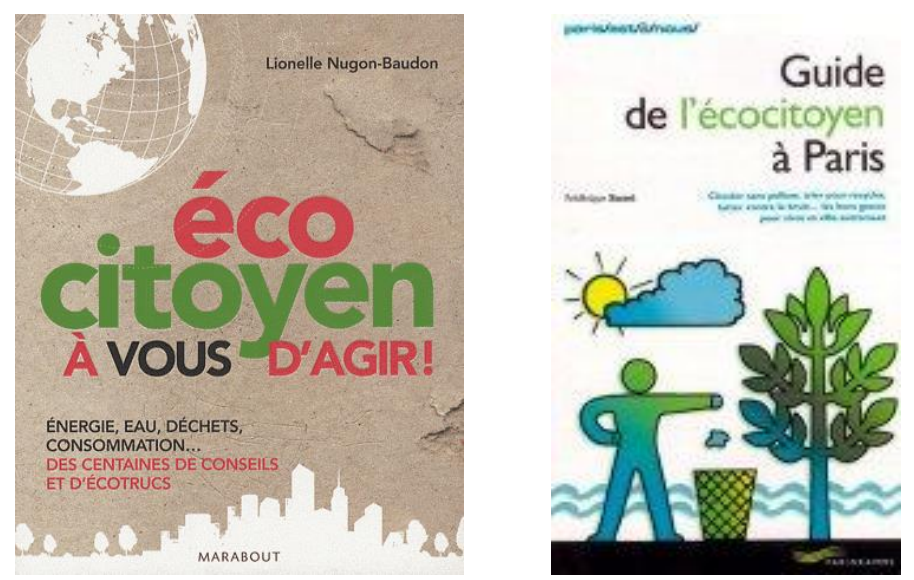

Fonte: www.greenrepublic.fr; acesso em 05/02/2010.

Se nossas sociedades atualmente litigam sob o regime de invocação do "sujeito empreendedor", então certamente esta não é a única posição de sujeito do presente com consequências significativas e constituídas pelo discurso.

Modos de subjetivação - Subjetivações reais

Aquilo que se delineia na superfície do discurso como uma posiçao de sujeito possível, insultada, desejada, exigida e que deve ser evitada e às vezes amparada de maneira dispositiva, raramente corresponde ao que os destinatários fazem desse endereçamento. Afinal, eles são colocados em requisitos de subjetivação muito complexos, contraditórios, variados, incoerentes, multidiscursivos, de práticas (da ação) e, em certo sentido, também “induzidos por coisas e corpos". Contra o pano de fundo do conceito de ação ou de ator delineada na tradição interpretativo-social-construtivista, pode-se presumir que aqueles abordados discursivamente irão (re)agir de acordo com suas próprias interpretações, experiências, relevâncias e graus de liberdade de ação. Isso pode se desdobrar em todo o espectro de possíveis formas de reação: como esforço para adotar a posição de sujeito desejada, como sua subversão, como uma interpretação errônea, como uma adaptação em partes, como uma reinterpretação, como ignorância, como contraposição altamente reflexiva ou cumprimento ingênuo etc. Analisar os modos reais de subjetivação (ou, dito de outra forma: as subjetivações) provavelmente não é em si Análise do Discurso, mas sim análise de mundos da vida, de campos de ação, de modos de ação e de experiências ou formas de experiências que demandam abordagens diferenciadas das ciências sociais. Ao mesmo tempo, esse nível de ação não pode mais ser analisado como se se 
KELLER, R. - Sobre a práxis da Análise do Discurso da Sociologia do Conhecimento

desenvolvesse apenas a partir de si mesmo. Uma vez que experiências, modos de ação, interações, práticas em campos sociais do cotidiano ou nos vários e diferenciados campos de práxis não são tratados como invenções genuínas dos atores ou simplesmente como receitas tradicionais experimentadas e testadas, mas sim como embutidas em discursos históricos e dispositivos entrelaçados - assim a pesquisa social empírica e interpretativa pode contemplar a relação entre as condições vividas do eu e do mundo, ou seja, as subjetivações vividas; e ela realiza isso de forma ainda mais convincente enquanto leva em consideração seus horizontes discursivos. Como demonstram por exemplo estudos qualitativos sobre a prática da consciência ambiental e do comportamento ambientalmente correto, os cidadãos tratados discursivamente como "écocitoyens" transitam num complexo campo de tensão entre apelos discursivos e demandas do cotidiano, a partir do qual geram diferentes (se não ilimitadas) apropriações e opiniões a respeito das posições de sujeito de conotação positiva do discurso ambiental (cf. POFERL 2004). Isso também pode significar o seguinte:

Eu assumo isto: não estou nem aí para a separação do lixo! Separar o lixo é uma besteira. Lixo é lixo. Só lixo. É para isso que existe a lata de lixo. A lata de lixo comum. Bem grande, pra caber tudo dentro. ${ }^{10}$ Fonte: Site "Fudder", Freiburg (www.fudder.de), acesso em $05 / 02 / 2010$.

A Análise do Discurso da Sociologia do Conhecimento visa disponibilizar as correspondentes possibilidades de conexão para análise dos modos concretos de subjetivação em sua mediação com os processos discursivos por meio de seus conceitos de análise e inserção teórica básica na tradição interpretativa e social-construtivista.

\section{Hermenêutica, análise interpretativa, conceitos de análise do}

\section{saber}

A ADSC insiste que a pesquisa sobre o discurso é, de maneira inevitável e incontestável, uma forma de trabalho de interpretação (KELLER 2005a: 273ss, KELLER 2005b). Como toda pesquisa sobre o discurso, ela é um discurso sobre discursos e requer (novamente, como toda pesquisa sobre o discurso) uma hermenêutica, ou seja, uma teoria da interpretação que esteja ciente de que os dados (e, portanto, também os textos) não falam por si, mas fornecem respostas às perguntas que lhe fizermos. Para

\footnotetext{
${ }^{10}$ Decidimos não reproduzir aqui a imagem da pessoa apresentada juntamente com essa declaração.
} 
KELLER, R. - Sobre a práxis da Análise do Discurso da Sociologia do Conhecimento

tanto, a ADSC segue as teorias básicas da compreensão do significado e do uso humano de símbolos. "Hermenêutica" não é de forma alguma um empreendimento reduzido à compreensão do significado que se pensa subjetivamente. Certamente existem tais posições no amplo campo da hermenêutica. Contudo, desde meados da década de 1990 a hermenêutica das ciências sociais (HITZLER \& HONER 1997) se refere de maneira bastante genérica ao projeto de reflexão sobre os processos científicos de interpretação e de esclarecimento dos mesmos como trabalho de interpretação e construção. Isso também se aplica às formas de análise de dados que se concentram na superfície do que é dito; e isso inclui programas de análise a partir dos quais (como na hermenêutica objetiva de Ulrich Oevermann ou na análise de conversação etnometodológica de maneiras muito diferentes) nada está além da investigação do "significado subjetivamente pretendido" (na tradição de Weber).

$\mathrm{Na}$ relação hermenêutico-interpretativa com a época atual, constrói-se o que se denomina na tradição francesa da teoria da ciência e do saber como uma "ruptura epistemológica" (Gaston Bachelard), ou seja, uma postura analítica que define seus próprios interesses de saber e aborda os dados de acordo com seus padrões, sem compreender ingenuamente a "autoafirmação" dos dados e tomá-los por uma verdade. A hermenêutica das ciências sociais de forma alguma significa uma prática de interpretação de dados que visa a um significado verdadeiro (e consistente), independente de se presumir por trás do texto a subjetividade de um autor ou uma autora ou a verdade objetiva das leis históricas. Antes, a hermenêutica das ciências sociais se refere como "atitude e ação" (SOEFFNER \& HITZLER 1994) à "compreensão da compreensão", ou seja, uma metodologia de pesquisa que, por um lado, reflete a posição do(a) intérprete e, por outro, desenvolve estratégias de interpretação de dados - por exemplo, na forma de um procedimento sequencial - que visam à rastreabilidade e objetivação social das etapas de interpretação. Isso pode ocorrer no âmbito de interesses de pesquisa e abordagens metodológicas de pesquisa social qualitativa ou interpretativa muito variados. ${ }^{11}$ Sempre se trata de problematizar a compreensão mais ou menos ingênua. Ronald Hitzler e Anne Honer formularam essa posição de maneira concisa:

O problema reflexivo básico do intérprete das ciências sociais é tornar transparente para si mesmo e para os outros a forma como entende aquilo que acha que entende, e como sabe o que acha que sabe. (...) Dito de forma metodológica: as abordagens da hermenêutica da ciência social inserem decididamente dúvidas no processo de

\footnotetext{
${ }^{11}$ Os conceitos “qualitativo" e "interpretativo" serão usados aqui como sinônimos.
} 
KELLER, R. - Sobre a práxis da Análise do Discurso da Sociologia do Conhecimento

compreensão: dúvidas sobre os pré-conceitos do intérprete, dúvidas sobre as certezas que se subsumem na vida cotidiana e na ciência e, por fim, dúvidas sobre explicações reducionistas. (...) Toda hermenêutica das ciências sociais, seja lá o que faça, problematiza fundamentalmente a suposição de que sabemos como algo "realmente" é, sem que sejamos capazes de compreender como é possivel saber tal coisa. (...) Seu objetivo é (...) despojar as operações básicas da pesquisa em ciências sociais $e$ a sua construção teórica da sua ingenuidade epistemológica, reconstruí-las e aclará-las. (HITZLER \& HONER 1997b: 23ss.)

Se entendermos a pesquisa sobre o discurso nas ciências sociais dentro da tradição foucaultiana como um projeto de pesquisa que enfoca o desenvolvimento, a estabilização e a mudança histórica dos discursos e seus efeitos de poder, então tal projeto inclui inevitavelmente um forte momento de reconstrução - pois de que outra forma se deveria descrever o esforço de analisar a maneira com que algo veio a se tornar o que vemos hoje? Por isso, toda perspectiva genealógica procede de maneira reconstrutiva. Claro, existem momentos de desconstrução embutidos nele: dados são fragmentados, contextos são desfeitos e recriados, o óbvio é despojado da sua obviedade e incorporado em novos conceitos e perspectivas. Uma pesquisa reconstrutiva do discurso corresponde totalmente àquilo que Foucault descreveu como sua atitude e tarefa da crítica - a análise da contingência histórica de construções apenas aparentemente objetivas e inevitáveis da realidade, e portanto do Esclarecimento [Aufklärung] em seu sentido mais tradicional para "expandir o repertório de ações das sociedades" (Hans Georg Soeffner). Desconstrução e reconstrução são processos analíticos que andam de mãos dadas na pesquisa do discurso na sociologia do conhecimento.

Dreyfus e Rabinow (1987) descreveram a posição de Foucault como "analítica interpretativa", que, de acordo com eles, de fato retoma elementos do estruturalismo e da hermenêutica, mas acaba superando ambas as abordagens. O conceito de interpretação se refere aqui àquilo que poderia ser considerado a questão teórica central ou a conclusão teórico-diagnóstica da análise. Ele não se refere às etapas práticas de pesquisa envolvidas no tratamento de dados, fontes, arquivos, ou à suposição básica de uma realidade que só é acessível por meio da interpretação (ou atribuição de significado). O fato de Foucault se distanciar das tradições da hermenêutica filosófica e literária, que buscam determinar a verdadeira natureza de um autor (inclusive seus abismos psicológicos ou sua marca de classe) ou o verdadeiro significado de um texto, mas não ter reservas absolutas quanto aos procedimentos interpretativos, pode ser comprovado no seu trabalho de edição de "Conflitos de família", feito em colaboração com a historiadora Arlette Farge, no qual 
KELLER, R. - Sobre a práxis da Análise do Discurso da Sociologia do Conhecimento

ambos criam categorias relacionadas ao texto que uma Grounded Theory certamente não usaria de forma diferente (cf. FARGE \& FOUCAULT 1989).

A recepção "dogmática” de Foucault (representada nos países de língua alemã, por exemplo, por Hannelore Bublitz, Hermann Kocyba, Petra Gehring ou Philipp Sarasin e algumas abordagens "pós-estruturalistas", como a tradição da teoria da hegemonia ou do pragmatismo linguístico francês) tende a ocultar a questão dos momentos interpretativos, entendida aqui como questão de trabalho interpretativo concreto sobre os dados, ou a tomar um posicionamento genérico "against interpretation" ["contra a interpretação"] (Susan Sonntag). Já expus acima que, do ponto de vista da sociologia hermenêutica do saber, toda referência a um dado empírico (ou seja, compilação e também avaliação de dados) demanda etapas reflexivas de interpretação. Por isso, a ADSC defende conectar a pesquisa sobre o discurso a algumas estratégias de análise do paradigma interpretativo ou de métodos qualitativos. As etapas de interpretação podem incidir, por um lado, na materialidade do discurso expressa em práticas, atores e dispositivos, e, por outro, nos vários momentos conteudísticos da estruturação (simbólica) relativa ao saber de enunciados e ordens do mundo. Falo de análise interpretativa para enfatizar que a pesquisa sobre o discurso relaciona diferentes formatos de dados e etapas de avaliação entre si, por exemplo, estratégias sociológicas mais clássicas de análise de caso individual, ou estudo de caso combinado com análises refinadas e detalhadas de dados textuais. Também falo de análise interpretativa porque, em contraste com outras abordagens de pesquisa social qualitativa, a ADSC não está interessada per se na unidade de significado de um documento individual (por exemplo, um texto), mas supõe que tal dado articula apenas pedaços ou "fragmentos" (Siegfried Jäger) de um ou mais discursos. É por isso que ela rompe a unidade da superfície material dos textos e enunciados e atribui os resultados da dissecação analítica e da análise fina interpretativa a vários discursos. Isso gradualmente cria o mosaico do discurso ou dos discursos examinados - certamente uma das modificações mais importantes da pesquisa social qualitativa de praxe.

No que diz respeito à análise da estruturação conteudístico-simbólica dos discursos, propõe-se a distinção acima mencionada entre padrões interpretativos, classificações, estruturas fenomenológicas, estruturas narrativas e repertórios de interpretação. Estes são conceitos gerais originados da tradição da sociologia do conhecimento ou que podem ser incorporados a ela, e que são, ao mesmo tempo, 
KELLER, R. - Sobre a práxis da Análise do Discurso da Sociologia do Conhecimento

particularmente adequados como conceitos de ponte quando se trata de investigar o debate com conhecimento gerado discursivamente em contextos práticos ou da vida cotidiana.

- A carreira das ciências sociais e a diferenciação no conceito de padrões interpretativos ou, de acordo com o conceito de frame no contexto angloamericano desde a década de 1980, não pode ser reproduzida aqui. A ADSC segue os métodos de aplicação embutidos na tradição da sociologia do conhecimento e da fenomenologia social que, por exemplo, questionavam padrões interpretativos para a saúde ou o trabalho de trabalhadores industriais, ou a mudança histórica do conceito de "amor maternal" (Yvonne Schütze) (cf. a literatura em KELLER 2003a). Padrões interpretativos são esquemas de interpretação para fenômenos, situações, acontecimentos e ações seculares. Assim, o corpo humano pode ser interpretado como uma máquina robusta ou como um composto orgânico frágil. O "amor maternal" (SCHÜTZE 1992) pode se desenvolver entre um cuidado protetor e emocional e refúgios ou a obrigação de promover a aquisição de habilidades na primeira infância (para mencionar apenas dois padrões interpretativos diferentes). Tecnologias podem ser interpretadas como sendo seguras ou (em princípio) arriscadas. Os padrões interpretativos conectam o factual ao normativo, a argumentação a exemplos e conclusões morais. O elemento do padrão se refere ao aspecto do que é típico - trata-se de figuras interpretativas gerais não apenas para fatos, mas também, por exemplo, para posições de sujeito usadas em atos e ações interpretativas concretas e que se manifestam em diferentes formas simbólicas e materiais: como cartuns, como frase ou contexto de frases, como fotografia, como encadeamento de práticas. Nos discursos, os significados não existem como partículas soltas e isoladas de signos, mas na forma desses padrões interpretativos. Na tradição da sociologia do conhecimento, os padrões interpretativos são apresentados como produtos coletivos, como elementos do repositório social de saber. Os discursos geralmente contêm vários padrões de interpretação interrelacionados; ao mesmo tempo, oferecem lugares para gerar novos padrões ou para transformar padrões existentes. $^{12}$

\footnotetext{
${ }^{12}$ Explicações sobre o procedimento concreto de análise sequencial no contexto de uma reconstrução de padrões interpretativos de análise do discurso podem ser encontrados em Keller \& Truschkat (2014).
} 
KELLER, R. - Sobre a práxis da Análise do Discurso da Sociologia do Conhecimento

- Um segundo desenvolvimento conteudístico dos discursos e que complementa o conceito de análise de padrões interpretativos, consiste na investigação das classificações (e, portanto, das qualificações) dos fenômenos acontecidos nelas e por meio delas. Classificações são formas mais ou menos elaboradas, formalizadas e institucionalmente estabilizadas de processos de tipificação social. Elas não classificam a realidade encontrada - no sentido de uma perspectiva representacionalista - em categorias adequadas, mas criam a experiência dessa realidade. $\mathrm{O}$ transcorrer normal das nossas rotinas diárias consiste num processo ininterrupto de classificação com base em elementos apropriados do repositório coletivo de saber. Como todo uso linguístico, o uso da linguagem nos discursos classifica o mundo, divide-o em certas categorias que fundamentam sua experiência, interpretação e tratamento. Entre os discursos há disputas para tais classificações, por exemplo, sobre como catástrofes técnicas (potenciais) devem ser interpretadas, sobre quais ofertas de identidade podem ser consideradas legítimas, sobre o que é um comportamento correto ou repreensível, sobre qual separação do lixo deve ser feita etc. Isso está associado a consequências prática específicas. Seu efeito depende, em última instância, de elas serem institucionalizadas na forma de dispositivos correspondentes e, assim, de conseguirem orientar a ação. A análise das "classificações e suas consequências" processadas discursivamente (BOWKER \& STAR 2000) está apenas começando a ser realizada na área da pesquisa do discurso.

- Além dos padrões de interpretação e das classificações, o conceito de estrutura do fenômeno possibilita um terceiro acesso, complementar ao nível de estruturação conteudística dos discursos. Já na fase constituinte da sociologia do conhecimento, Karl Mannheim introduziu o termo "estrutura de aspecto" para descrever a forma como os fatos são construídos, ou seja, o que é registrado em relação a um fenômeno. Os componentes de tal estrutura de aspecto são, de acordo com Mannheim, os termos usados, incluindo sua diferença de significado com relação a outros termos possíveis, a relação entre esses termos, esquemas causais, a “ontologia pressuposta” etc (MANNHEIM 1969: 234). O conceito de estrutura do fenômeno pressupõe tais considerações e as relaciona ao fato de os discursos nomearem diferentes elementos ou dimensões de seu objeto na constituição da sua relação referencial (ou seja, seu tema), e os combinam numa forma específica, 
KELLER, R. - Sobre a práxis da Análise do Discurso da Sociologia do Conhecimento

uma constelação fenomenológica. Isso de forma alguma denota as qualidades essenciais de um objeto do discurso, mas sim as atribuições discursivas correspondentes. A reconstrução analítica da estrutura do fenômeno se orienta por dois aspectos: a revelação dimensional está relacionada à composição geral da forma do fenômeno. As dimensões a partir das quais um fenômeno se constitui discursivamente podem ser mais ou menos iguais ou diferentes em um campo discursivo entre discursos diferentes e concorrentes entre si. A realização conteudística das dimensões reconstruídas na primeira etapa pode variar consideravelmente dependendo da causa contextual e situacional de um acontecimento discursivo e também entre discursos. A Análise do Discurso da Sociologia do Conhecimento visa aqui uma tipificação dos conteúdos, das regras ou princípios do que se questiona como conteúdo e de como isso acontece, não da compilação sumária de tudo que foi dito nas citações originais - o que certamente pode ser usado para fins de apresentação e ilustração. As estruturas de fenômeno mudam com o decorrer do tempo. As estratégias de busca correspondentes podem, portanto, não apenas focar no "congelamento" de uma estrutura de fenômeno específica num momento $\mathrm{X}$, mas também tornar objeto de pesquisa $\mathrm{O}$ desenvolvimento, a mudança e a comparação entre estruturas de fenômeno, ou seja, as estruturas de fenômeno permitem uma representação do contexto de enunciação de um discurso, a partir do qual inúmeras outras questões (sobre sua gênese, constelações opostas, consequências dispositivas) podem ser investigadas.

- Devemos mencionar aqui um último momento da forma conteudística dos discursos: aqueles momentos estruturantes de enunciados e discursos podem ser designados como estruturas narrativas por meio das quais vários padrões interpretativos, classificações e dimensões da estrutura de fenômenos se relacionam de maneira específica. A investigação das estruturas narrativas (plots, story lines, fios narrativos) de discursos pode distinguir narrativas principais e secundárias, narrativas gerais ou generalizadas de histórias ilustrativas de documentações e de evidências. As estruturas narrativas não são simplesmente técnicas de ligar elementos linguísticos, mas sim um "mise en intrigue" (Paul Ricoeur), como um ato configurativo de ligar signos e enunciados disparatados na forma de narrativas, um modo fundamental da ordem humana de experiência do 
KELLER, R. - Sobre a práxis da Análise do Discurso da Sociologia do Conhecimento

mundo. ${ }^{13}$ Elas constituem condições de mundo (contestáveis) como narrativas nas quais existem atores e atuantes, acontecimentos, desafios, sucessos e derrotas, "bons" e "maus" etc.

Em relação à criação e ao "processamento" de um corpus de dados no contexto da pesquisa empírica do discurso, as estratégias de trabalho propostas, entre outras, pela Grounded Theory (como theoretical sampling ["amostragem teórica"], "contraste máximo" e "mínimo", coding [“codificação"] etc.) fornecem instruções úteis. Elas se referem à seleção de dados para análise detalhada bem como para a combinatória analítica de resultados individuais (cf. StRAuss 1998, KELLER 2003a). A fim de evitar malentendidos, isso não torna a pesquisa do discurso uma variante da Grounded Theory. Ela aproveita apenas algumas sugestões desse contexto. Vou me dedicar ao processo correspondente na última seção.

\section{Procedimentos}

Em outra publicação (KELLER 2003a), demonstra-se como a ADSC concebe projetos de pesquisa do discurso das ciências sociais em amplo acordo com o design reflexivo da pesquisa social empírica qualitativa e interpretativa. Com isso não se propõe um programa padrão e que deva sempre ser executado exatamente dessa maneira (e talvez até completamente dessa maneira) para que se possa falar de análise do discurso na sociologia do conhecimento. Toda implementação é obrigada a fazer ajustes ou traduções da perspectiva básica relacionada aos assuntos e questionamentos de interesse. A seguir vamos recapitular alguns pontos importantes dos procedimentos:

A pesquisa do discurso na sociologia do conhecimento entende textos, práticas ou artefatos não como produtos de estruturas de caso "subjetivas" ou "objetivas", mas sim como manifestações materiais de ordenações de saber sociais e, portanto, como a base mais importante para uma reconstrução sociológica do saber da produção, da estabilização e da mudança dos estoques coletivos de saber. O objeto discurso demanda uma adaptação específica dos métodos de pesquisa social qualitativa e de análise de texto:

- Uma diferença importante entre as análises do discurso e outras abordagens da pesquisa social interpretativa reside na suposição de contextos de referência

\footnotetext{
${ }^{13}$ Cf. a discussão em Viehöver (2001).
} 
KELLER, R. - Sobre a práxis da Análise do Discurso da Sociologia do Conhecimento

intertextuais na forma de regras ou recursos, ou seja, estruturas de produção de enunciados. A ocorrência de enunciados individuais não representa "tipos" individuais (como na pesquisa biográfica); em geral, eles não representam de maneira alguma apenas um discurso - e este também não em sua totalidade.

- Discursos estão sempre integrados num contexto interdiscursivo e fazem referência a formações discursivas históricas diacrônicas e sincrônicas. Assim, devem ser reconstruídos a partir de enunciados individuais. Essa agregação de resultados individuais em informações sobre "o" discurso marca a diferença central para a maioria das abordagens qualitativas, que pressupõem, para cada texto (em geral entrevistas), uma estrutura de sentido ou caso fechada e consistente em si mesma, ou seja, consideram um texto como um documento completo de exatamente um caso. A representação heterogênea e parcial de elementos específicos do discurso é típica da perspectiva analítico-discursiva dos tipos naturais de texto; portanto, os resultados da análise de textos individuais devem estar relacionados entre si.

- Análises de Discurso nas ciências sociais se veem diante do problema de grandes quantidades de texto. Os procedimentos interpretativos de análise de dados são aplicados principalmente a pequenas quantidades de texto, e são adequados apenas até certo ponto para os extensos corpora textuais da pesquisa do discurso. Por isso, não podem ser simplesmente transferidos, mas sim adaptados aos interesses de pesquisa da análise do discurso. A extensão que o material empírico deve ter para que seja possível produzir enunciados "robustos" sobre o(s) discurso(s) de interesse específico resulta essencialmente dos questionamentos, ou deve ser justificado com relação a eles. Em geral, o material desenvolvido e compilado gradualmente pode ser contemplado a partir de dois pontos de vista. Por um lado, serve para informação sobre o campo (aspecto de saber ou informação). Informação divulgada pela mídia, publicações de livro, expertises fornecem informações sobre importantes acontecimentos e documentos de referência, atores(as), por exemplo organizações relevantes, tiragens, locais de produção da pesquisa ou outras tomadas de posição etc. Nesse sentido, "dados disponíveis", como textos ou dados produzidos especificamente para a pesquisa (como entrevistas), são eles próprios apenas arenas em rede ou entrelaçadas que 
KELLER, R. - Sobre a práxis da Análise do Discurso da Sociologia do Conhecimento

situam uma afirmação real num contexto discursivo mais amplo. ${ }^{14}$ Por outro lado, os dados assim obtidos (uma série de enunciados em diferentes formatos de signos) constituem a base da reconstrução dos discursos, dos seus meios materiais e linguísticos e dos seus significados. A materialidade dos enunciados afeta, por exemplo, sua forma e distribuição específicas, mas também os recursos mobilizados para sua criação. Os meios linguístico-retóricos se relacionam com os aspectos formais de sua aparência. O nível dos significados de conteúdo está relacionado ao seu conteúdo expressivo no sentido de Foucault, ou seja, aos padrões de organização de significado que dão orientação específica às formas de signo concretamente utilizadas (em As palavras e as coisas de Foucault, por exemplo, as figuras do saber que ele chamou de "episteme"). Aqui deve-se justificar a importância dos documentos analisados em relação ao(s) discurso(s): É um enunciado típico? É um documento no qual se distingue "algo novo"? Um documento no qual se incorpora "outra coisa"? Um documento central a que frequentemente se faz referência no discurso? Um documento marginal com importância mais passageira? Um documento que, em parte ou no todo, poderia ser atribuído a outro discurso etc.? Nesse sentido, todo o material gradualmente coletado funciona como um contexto interno (com base na imanência de um discurso) ou externo (dentro de uma arena de discursos concorrentes ou conflitantes em relação à questão de em que discurso parcial está localizado um documento) para os dados individuais examinados em detalhe.

A questão de quando e em que nível se pode falar de um discurso não pode ser formulada independente dos respectivos interesses de pesquisa. A unidade discursiva ou a coerência dos textos pode diminuir à medida que o contexto em que são falados ou inscritos não está mais relacionado, em sua condição de destinatário, a um discurso especial, mas ao "público”. Muitos documentos de texto de discurso público, como laudos periciais no processo de formulação de políticas, mas também livros ou reportagem com informação de fundo na mídia, são compostos de vários discursos especiais. Por exemplo, num livro de não ficção, a introdução pode aparecer como um discurso de reforma política, o capítulo de fatos como um discurso científico e as conclusões como um discurso de ciências sociais. No entanto, num caso específico esses trechos de diferentes

\footnotetext{
14 "Dados naturais" não existem; de maneira correta, enunciados de primeira ordem (produzidos 'no campo') serão transformados em dados específicos para uma pesquisa específica por meio de um enfoque analítico específico de "segunda ordem".
} 
KELLER, R. - Sobre a práxis da Análise do Discurso da Sociologia do Conhecimento

discursos podem se apresentar como o contexto de um único discurso híbrido e também podem ser tratados como tal.

Formatos de dados e construção de corpus

Vários formatos de dados podem ser considerados para a análise do discurso da sociologia do conhecimento. Uma distinção pode ser feita entre dados textuais (livros, textos jurídicos, instruções, artigos de jornais, atas de entrevista e debates, etc.), dados audiovisuais (imagens, filmes, música), objetivações em objetos (por exemplo, edifícios de igrejas, cálices, batina etc.) e práticas sociais observáveis (por exemplo, protestos, gestos simbólicos). ${ }^{15}$ Trata-se de diferentes elementos de relações dispositivas (infraestruturas) da produção do discurso e da intervenção discursiva no mundo, isto é, não se trata de elementos isolados e arbitrários do discurso. A construção do corpus mais ou menos extensa em casos individuais demanda recursos de tempo, pessoais e recursos financeiros. Requer monitoramento e questionamento constantes quanto à composição pretendida e ao grau necessário de completude. Isso inclui, por exemplo, verificar até que ponto os recursos utilizados - como serviços de recorte de imprensa, arquivos - procedem de forma seletiva, ou seja, documentam apenas trechos específicos sobre e de textos que devem ser complementados por outras fontes. Em muitos casos, a formação do corpus já pode se basear em ideias de theoretical sampling (STRAUSS 1998: 70ss). Este conceito da Grounded Theory indica que não apenas a análise mas também a compilação de dados ocorre de acordo com critérios baseados na teoria, ou seja, critérios refletidos. Assim, no contexto do ADSC, por exemplo, é possível primeiramente ser feita uma cartografia dos locais e locutores importantes de uma arena de discurso que seja foco de um projeto de pesquisa. Uma cartografia dessas pode, é claro, ser criada histórica e genealogicamente, ou seja, para diferentes tempos ou fases de um campo. Além disso, ela deve estar atenta a quais posições de locutor são tomadas e em quais públicos elas aparecem (ou são excluídas). A coleta de dados posterior pode então se orientar por uma visão geral abrangente de todos os locutores. Por outro lado, também é possível, com base numa coleta de dados (depoimentos, textos), abordar o campo dos locutores envolvidos de maneira reconstrutiva, ou seja, olhar para os atores que estão presentes nos discursos

\footnotetext{
${ }^{15}$ Variantes da análise de visualizações no contexto da ADSC foram discutidos em Keller (2016).
} 
KELLER, R. - Sobre a práxis da Análise do Discurso da Sociologia do Conhecimento

midiáticos enquanto depoimentos, seguir as referências em laudos periciais etc. - e com isso se tornar sensível a quem não aparece (embora haja boas razões para que apareça).

\section{Contextualização e materialidade de um enunciado}

Análises de Discurso remetem preferencialmente a enunciados que são pré-produzidos "no campo" (textos de mídia, livros especializados, talk shows, pareceres, textos e acontecimentos audiovisuais gravados) que inicialmente não foram produzidos para ou pela pesquisa mas se tornam dados para a pesquisa por meio de acesso analítico, e combinam sua análise com suas próprias pesquisas (em especial entrevistas, incluindo discussões em grupo), bem como os resultados das pesquisas de campo descritas acima. A pesquisa do discurso da sociologia do conhecimento, no entanto, não é pura pesquisa de texto: ela está interessada na conexão social entre o uso da linguagem ou de signos e a produção de significado como base para a objetificação dos repositórios sociais de saber. Um primeiro passo importante na investigação no que diz respeito aos enunciados individuais é, portanto, a análise de sua situação social em diferentes contextos situacionais, institucionais-organizacionais e sociais. Pode-se partir da questão de quem produz um enunciado, onde e para quem. As posições e relações dos produtores e receptores de enunciados são registrados; os settings institucionais e suas regras; acontecimentos encenados e "naturais" que se tornam motivo para a produção de declarações (por exemplo, catástrofes, processos de tomada de decisão parlamentar, reformas universitárias e outros "problemas urgentes"); contextos midiáticos do seu aparecimento (por exemplo, livros especializados, livros de popularização da ciência, jornais, discussões, reportagens de televisão, internet); contextos sociais mais gerais (conjunturas econômicas, científicas, socioculturais); finalmente, também constelações de poder existentes num campo discursivo. Os diferentes níveis de contexto se relacionam em forma de funil com um ou vários documentos dentro do corpus. Nesta etapa de investigação, é importante não pressupor apressadamente uma conexão direta entre o contexto e o documento de texto com base em saberes anteriores ou pré-julgamentos, mas considerar as duas dimensões analiticamente de forma independente ou trabalhar sua relação apenas no processo de análise.

A questão da forma material de um enunciado é direcionada ao meio [Medium] em que aparece, ou seja, como ela é articulada e disseminada. Por exemplo, podem ser registrados o tipo de texto, tiragem, editora, canais de distribuição, arena de recepção: é

Pandaemonium, São Paulo, v. 24, n. 44, set.-dez. 2021, p. 475-518 
KELLER, R. - Sobre a práxis da Análise do Discurso da Sociologia do Conhecimento

um discurso parlamentar, um texto de jornal, um livro, um documentário de televisão? Qual é sua respectiva dimensão? Quem pode ser potencialmente alcançado por ele? Que recursos foram usados para produzir esse enunciado? Em que campo de poder institucional ele aparece?

\section{A análise interpretativa do conteúdo}

A captação e a reconstrução interpretativo-analítica do conteúdo dos enunciados estão intimamente ligadas à etapa descrita acima, e muitas vezes marcam a diferença entre as Análises do Discurso linguísticas e as das ciências sociais (KELLER 2006). Enquanto uma abordagem da linguística de corpus faz inicialmente uma extensa compilação de corpus, em geral baseada em palavras-chave (frequentemente milhares de textos), e, em seguida, testa hipóteses específicas sobre ela ou gera indutivamente hipóteses sobre padrões de linguagem, a formação de corpus dentro do escopo de uma ADSC se dá sucessivamente ao longo de uma lógica diferente de critérios de seleção (por exemplo, não por meio de conceitos mas de atores, momentos e acontecimentos) e em análises interpretativas individuais incluídas na decisão sobre quais documentos devem ser examinados em seguida. Trata-se, portanto, sempre do exame intensivo de tais documentos individuais, a fim de decifrar padrões recorrentes de significado na produção de enunciados a partir deles. Leva-se em consideração que o significado de uma palavra só pode ser compreendido no seu contexto de uso e varia de acordo com seu uso. A análise interpretativa da ADSC visa criar uma matriz detalhada ou um registro esquemático de enunciados que sirva de base para a posterior formação de hipóteses sobre os conteúdos, funções e efeitos de um discurso. Em seguimento à diferenciação entre o significado subjetivo, o situacional e o socialmente típico de um enunciado, tal como se faz no contexto da sociologia hermenêutica do saber, ${ }^{16}$ trata-se nesse processo de reconstrução do nível da tipologia social. O nível de atribuição subjetiva de significado é de importância secundária para o programa de pesquisa do discurso desenvolvido aqui. A pesquisa do discurso não levanta questões sobre uma intenção subjetiva autêntica e o significado (idiossincrático) de um enunciado para produtores e produtoras de texto. Ela leva em consideração o significado situacional no contexto direto das expressões mas, em

\footnotetext{
${ }^{16}$ Em um exemplo clássico: uma certa obra de palco (como o Fausto de Goethe) é minha peça favorita desse autor (significado subjetivo); é a peça ensaiada pelos alunos dessa escola ou tratada em sala de aula (significado situacional); é a peça central da literatura clássica alemã (significado socialmente tipificado).
} 
KELLER, R. - Sobre a práxis da Análise do Discurso da Sociologia do Conhecimento

última análise, visa ao conteúdo geral, que pode ser descrito como sendo mais típico no contexto de um coletivo social; a ligação do nível situacional com o geral permite que se reconheça e reflita sobre diferentes "maneiras de uso" de tipificações. Por exemplo: a interpretação de um acontecimento como uma "catástrofe" pode estar ligada a diferentes conclusões - melhor tecnologia, recusa de um caminho de desenvolvimento técnico, destino inevitável. Como parte do processo de reconstrução previsto, várias perguntaschave são feitas sobre um contexto de enunciados: Qual é o tema de um texto? Ele é tratado com base em que categorias, argumentos, classificações etc.? Quais subtemas são apresentados como relevantes? Quais são os elementos fundamentais desse enunciado? Existem exemplos, modelos, repetições de enunciados e conceitos? Qual é o significado do vocabulário usado em contraste com outros conceitos usados no campo discursivo correspondente? Várias abordagens estão disponíveis para a decomposição analíticointerpretativa de textos. Isso também se aplica à apresentação de resultados individuais e gerais, por exemplo em forma tabular, como texto corrido, gráficos ou na forma de uma "estrutura em árvore", uma rede semântica. No que diz respeito à análise interpretativaanalítica detalhada, a Grounded Theory também oferece sugestões úteis para o manuseio prático do material de dados.

\section{Análise detalhada}

A análise detalhada de acontecimentos significativos é um ato interpretativo que se baseia nas competências do(a) pesquisador(a). ${ }^{17}$ Requer muitos recursos e, via de regra, não pode incluir todos os dados do corpus, mas deve fazer uma seleção sistematicamente refletida e bem fundamentada de textos ou partes do texto dentro do corpus, ou seja, submeter o corpus de dados a outras restrições, especialmente no que diz respeito à exigência de se produzir quaisquer enunciados sobre um discurso. Deve-se cuidar para que os dados selecionados do corpus tenham uma certa amplitude, mas também comparabilidade, a fim de evitar ou pelo menos enfraquecer o problema da comparação não intencional de "alhos de dados" com "bugalhos de dados": um folheto não pode ser colocado diretamente ao lado de um laudo pericial; uma notícia ou um comentário difere consideravelmente de uma reportagem jornalística de várias páginas. Vários critérios estão disponíveis para esta etapa de condensação controlada dos dados a serem analisados. Isso inclui a orientação

\footnotetext{
${ }^{17}$ As explicações a seguir referem-se a dados textuais e audiovisuais. Veja também Keller (2016b).
} 
KELLER, R. - Sobre a práxis da Análise do Discurso da Sociologia do Conhecimento

refletida por textos, passagens, atores e acontecimentos principais cuja importância pode ser demonstrada a partir do próprio material de dados. Outros critérios de seleção seriam a cobertura do espectro de atores relevantes ou de opinião da mídia de massa. Consequentemente, a seleção de dados para análise detalhada é um processo de pesquisa aberto e orientado por critérios que não deve levar à criação de um subcorpus definitivo dentro de todo o corpus, mas que percorre gradualmente e registra a gama de todo o material de dados. Dependendo das análises detalhadas individuais, novos critérios podem surgir para uma seleção posterior. Para essas etapas de seleção sucessivas e relacionadas oferece-se uma orientação sobre a Grounded Theory (por exemplo, STRAUSS \& CORBIN 1996, STRAUSS 1998). Em primeiro lugar, a amostragem orientada pela teoria e os princípios de contraste mínimo e máximo desempenham (novamente) um papel importante. O objetivo é justificar a seleção dos documentos a serem utilizados para a análise detalhada do próprio processo de pesquisa: começa-se com um documento que parece ser "significativo" e, em seguida, busca-se no corpus de dados por uma ocorrência de enunciado que seja muito diferente (contraste máximo) ou comparativamente semelhante (contraste mínimo). A orientação para o contraste máximo permite apreender gradativamente todo o espectro do(s) discurso(s) dentro de um corpus e, assim, demonstrar vários discursos sobre um tema ou seus componentes heterogêneos dentro de um discurso. O contraste mínimo visa reconstruir a subárea registrada da forma mais precisa e completa possível, até que sua análise finalmente pareça estar "saturada". O processo de seleção da theoretical sampling ("amostragem teórica") é realizado até que análises adicionais não forneçam mais nenhum saber sobre todo o corpus ou sobre as perguntas de pesquisa relacionadas a ele. Os resultados das análises detalhadas são então agregados para formar enunciados gerais sobre o discurso ou discursos.

O procedimento para análise de dados é baseado na lógica de pesquisa aberta da pesquisa social interpretativa. A análise interpretativa desenvolvida pela ADSC compreende, em princípio e em relação a uma única ocorrência de enunciado, a análise de sua situação e sua forma material, a análise da estrutura formal e linguístico-retórica e a reconstrução interpretativo-analítica do conteúdo dos enunciados. Com as questões sobre o que e o como em termos de conteúdo, aborda-se a dimensão do significado de um enunciado ou discurso, bem como os modos de seu aparecimento. O uso da linguagem conceitos (categorias), classificações, visualizações (gráficos), metáforas, argumentos, marcadores de ator, marcadores de ação etc - sempre se refere a um horizonte ou contexto 
KELLER, R. - Sobre a práxis da Análise do Discurso da Sociologia do Conhecimento

de significado no qual faz sentido, que por sua vez é produzido pelo seu uso. Portanto, qualquer uso da linguagem sugere uma existência específica de fenômenos seculares. A demonstração de tal conteúdo deve condensar e tipificar os enunciados originais em maior ou menor grau, por exemplo, para formar estruturas narrativas ou plots, padrões interpretativos, classificações, estruturas de fenômeno e repertórios de interpretação. Nos discursos, os significados não existem como partículas soltas e incoerentes de signos, mas sim em formas estruturadas, como componentes pré-tipificados do saber coletivo que podem ser tipificados a partir da perspectiva da observação no processo de reconstrução.

A análise dos dados individuais começa com uma leitura simples ou repetida, que pode ser seguida por paráfrases do conteúdo. Para a análise individual, aqui também são úteis sugestões do programa de pesquisa da Grounded Theory. Além da já mencionada theoretical sampling, há também os conceitos de codificação, comentários $e$ memorandos. Não se trata de adotar esses conceitos tal como o são na pesquisa do discurso; ao contrário, como opções de sensibilização eles requerem uma adaptação mais ou menos extensa aos propósitos analíticos do discurso. As várias estratégias de codificação (qualitativa) visam à condensação conceitual de passagens individuais do texto dentro de documentos, tanto em termos de agrupamento analítico quanto de interpretação. Na pesquisa do discurso, a direção ou objetivo dessa compressão é dada pelos questionamentos específicos e conceitos relacionados (por exemplo, blocos de construção da estrutura do fenômeno, posições do sujeito, práticas, padrões interpretativos). Comentários (uma espécie de "pequenas notas de acompanhamento") podem (e devem) registrar os critérios de acordo com os quais um determinado código foi formulado e atribuído a uma passagem de texto. Memorandos são notas mais ou menos extensas feitas durante o processo de investigação e nas quais se registra outras considerações, ideias, insights e hipóteses advindas com relação a uma passagem de texto específica ou uma codificação. Os memorandos são, portanto, parte de um caderno de acompanhamento de pesquisa. Uma análise detalhada é geralmente realizada em várias etapas que se dirigem em movimentos pendulares ao encontro e em recuo do texto: começando com a leitura de documentos individuais, procede-se a paráfrases, à análise de contexto e à dissecação analítica, à interpretação detalhada e, finalmente, a um resumo. 
KELLER, R. - Sobre a práxis da Análise do Discurso da Sociologia do Conhecimento

No contexto da ADSC, proponho o uso de procedimentos de análise de sequência e alguns outros empréstimos da Grounded Theory. ${ }^{18} \mathrm{O}$ princípio da análise de sequência consiste primeiramente em traçar o maior número possível de hipóteses de interpretação para frases individuais, até chegar a seções inteiras do texto ou todo o texto, seguindo o fluxo do texto no que diz respeito às questões de interesse (cf. KELLER \& TRUSCHKAT 2014). Estes são verificados quanto à adequação na continuação imediata do texto, descartados, retidos ou especificados com mais precisão. O procedimento de análise de sequência não é específico dessas abordagens, mas uma estratégia de análise há muito ancorada na pesquisa qualitativa, com raízes na análise da conversação, na Grounded Theory e na hermenêutica objetiva. O que isso significa no contexto da ADSC? Numa primeira etapa, deve-se selecionar as seções de um texto ou de um dado audiovisual que serão submetidas à análise detalhada de sequência. Essa seleção é essencialmente determinada pelos questionamentos de pesquisa. No caso de textos longos, pode conter títulos, índices, introduções, capítulos selecionados, palavras finais etc; no caso de enunciados mais curtos, podem ser realizadas análises completas de uma unidade de enunciado. A análise de sequência é essencialmente uma tecnologia disciplinadora que supostamente evita que se percorra constantemente um documento ou compreenda um texto a partir do final, ou seja, a partir do ponto que aparentemente determina "em que consiste a coisa toda". Em certo sentido, é uma leitura desconstrutiva. A análise de sequência significa interpretar um enunciado ao longo de seções de significado e criar várias leituras sobre o que esta seção trata ou que resposta ela fornece à pergunta de pesquisa, pois o objetivo desta interpretação e, portanto, das leituras é derivado das perguntas de pesquisa. Isso significa que um mesmo documento pode ser analisado de maneiras muito diferentes com base em questões diferentes. As leituras não precisam ser formuladas na forma de frases; eles também podem aparecer como nomes, conceitos, códigos. A atribuição de um código para uma passagem de texto de acordo com o entendimento de codificação da Grounded Theory seria um exemplo de registro de uma leitura que é preferida a outras. Esse é o terceiro elemento disciplinador importante da análise de sequência: trata-se de desenvolver muitas leituras e, em seguida, fazer uma seleção justificável e bem fundamentada - ou seja, ser capaz de dizer por que esta ou aquela categoria foi atribuída de acordo. Isso também não impede que se atribua

${ }^{18}$ Cf. as palavras-chave "linhas mestras", a "análise detalhada" feita frase por frase e a "codificação (aberta)" em Strauss (1998).

Pandaemonium, São Paulo, v. 24, n. 44, set.-dez. 2021, p. 475-518 
KELLER, R. - Sobre a práxis da Análise do Discurso da Sociologia do Conhecimento

diferentes leituras a um enunciado e as deixe em pé de igualdade. Esse pode ser o caso, por exemplo, quando se trata de determinar um enunciado por meio da análise do conhecimento e quando se trata de denominar a função desse enunciado no contexto de um discurso.

Isso será brevemente ilustrado adiante para uma reconstrução do padrão interpretativo. Idealmente, este é um processo de grupo através do qual certas interpretações podem ser gradualmente excluídas e uma única pode ser socialmente objetivada como "adequada". Neste contexto, "adequada" significa que a hipótese obtida ou o padrão de interpretação reconstruído é mais capaz de descrever o significado da passagem de texto relevante e, portanto, o padrão interpretativo que estrutura uma unidade de codificação de uma maneira específica do discurso, em comparação com os outros padrões interpretativos descartados. Ao mesmo tempo, o trabalho de interpretação inicialmente extenso visa evitar a projeção dos próprios preconceitos sobre um texto; é, portanto, uma estratégia de autocontrole metódico. O(a) pesquisador(a) denomina os padrões de interpretação; ao fazer isso, às vezes podem ser usados conceitos dos próprios textos examinados. Uma análise correspondente de diferentes textos serve para reconstruir as variações contidas no material para um interesse de pesquisa específico e, assim, determinar os padrões que ocorrem no campo correspondente - por exemplo, na forma de diferentes "tipos". Esse procedimento é econômico para a pesquisa na medida em que os efeitos de saturação relacionados aos dados ocorrem de maneira relativamente rápida - o número de variações é limitado. Assim, pode ser suficiente avaliar algumas entrevistas ou textos relacionados a uma determinada pergunta de pesquisa para cobrir adequadamente o campo de investigação. De modo análogo, as análises de sequência podem estar relacionadas à elaboração de estruturas de fenômenos (tanto na sua compreensão dimensional quanto na execução do conteúdo).

\section{Exemplos de atribuição de padrões de interpretação e de enunciados (KELLER 1998)}

Padrão interpretativo de tecnologia "risco" (debate alemão sobre lixo)

Como a mais moderna planta de incineração de resíduos na Alemanha, quiçá no mundo, foi colocada em operação "quente" no outono passado em Augsburgo uma planta que custou mais de 900 milhões de marcos. Na semana passada, o teste 
KELLER, R. - Sobre a práxis da Análise do Discurso da Sociologia do Conhecimento

terminou abruptamente. Foram proferidas palavras que o leitor de jornal só deve conhecer de reatores nucleares: rachaduras em um tubo de pressão de vapor, vazamentos na tubulação de água, desligamento de emergência. E, claro: os limites de poluição ambiental permitidos por lei não foram ultrapassados. Não podemos esquecer: toda tecnologia está sujeita ao fracasso - quanto mais complexa, mais sujeita a falhas, um truísmo. (Süddeutsche Zeitung, 05/05/1994)

Este padrão interpretativo, que se desenvolveu em relação à energia nuclear em particular, baseia-se na "normalidade dos desastres" (Charles Perrow), na ocorrência do "risco residual", na incalculabilidade de efeitos colaterais (riscos para a saúde e ambientais) e na falta de oportunidades para evitar danos. Tecnologias complexas são inerentemente instáveis e perigosas. O progresso técnico não pode resolver esses problemas, mas leva a mudanças no risco. A cultura de risco da sociedade industrial, que de outra forma parecia imutável, está sendo questionada. Estratégias tecnológicas de ação são rejeitadas em favor de medidas políticas.

"Risco (tecnológico)" é um padrão interpretativo que pode estar relacionado a tecnologias ou áreas temáticas muito diferentes. Ele entrou no debate alemão sobre o lixo na década de 1980; contudo, não aparece no debate francês sobre o lixo. Este padrão interpretativo, usado nos discursos correspondentes como um elemento de afirmação, pode aparecer em formas superficiais muito diferentes: como foto, clipe de filme, declaração numa entrevista, estatística ou gráfico, colagem e montagem ou mesmo como uma conexão entre palavras e frases.

$\mathrm{Na}$ pesquisa sobre o discurso, unidades de dados individuais têm o status de documentos de discurso ou "fragmentos de discurso" (JÄGER 1999: 188ss). Em tal documento não há necessariamente um único discurso, e este não está totalmente representado. Fragmentos de discurso contêm partes compatíveis de discursos. Para se chegar a enunciados sobre o(s) discurso(s) em um campo discursivo, os resultados das análises detalhadas individuais devem ser agregados no processo de pesquisa. Essa é uma conquista construtiva de pesquisadores e pesquisadoras que pode ser entendida como uma generalização abstraída das peculiaridades do caso individual, de modo análogo à formação de tipos das ciências sociais. A partir da abordagem metodológica da pesquisa social qualitativa, não se pode estabelecer empiricamente antes de uma investigação nem mesmo antes do conhecimento prévio dos diferentes "campos da mídia" ou constelações de atores - a quantidade de discursos diferentes passíveis de serem 
KELLER, R. - Sobre a práxis da Análise do Discurso da Sociologia do Conhecimento

encontrados num campo específico de investigação e nem os elementos interpretativos ou regras de formação que os estruturam. ${ }^{19}$

Os resultados das várias etapas - isto é, a análise interpretativa, a análise da contextualização e da forma material, bem como a consideração dos elementos formais e retórico-linguísticos - são então relacionados entre si, na medida em que isso seja relevante para as questões de pesquisa. Finalmente, os resultados da análise detalhada são colocados num outro horizonte de interpretação - por exemplo, questões de poder ou hegemonia, o papel de atores individuais e acontecimentos no discurso ou campo discursivo etc. Isso também se aplica ao se responder às perguntas sobre as possíveis causas, condições estruturais e efeitos de processos de discurso específicos. Em termos mais gerais, trata-se também de relacionar os resultados da análise de dados com o conhecimento de contextos, processos sociais etc, se e na medida em que os questionamentos rastreados assim o exigirem. Em última análise, uma investigação também pode ser considerada convincente, surpreendente, inovadora, estimulante se não se basear nos critérios habituais, mas procurar, encontrar e abrir novos caminhos para outros.

Na apresentação dos resultados, a pesquisa do discurso tem sido até agora muito textual, dominada por uma sequência de passagens de texto narrativo que formulam os resultados em texto contínuo e os comprovam por documentos de texto embutidos (citações). Com exceção da preparação tabular das estruturas de discurso relacionadas ao conteúdo, quase não se usa nenhuma visualização gráfica. Certamente há uma necessidade de representações experimentais (veja os exemplos em KELLER 1998). Em princípio, a apresentação dos resultados enfrenta o mesmo problema ou dilema de todas as formas de pesquisa social (qualitativa): é verdade que os métodos de análise podem e talvez também devam ser representados por meio de exemplos em unidades de enunciados individuais, de modo que o próprio processo de análise seja compreensível e transparente em termos da margem de manobra possível. Porém, devido à fundamental impossibilidade de fixação por escrito, não é possível mapear todo o processo de reconstrução, nem as fases de geração de ideias, raciocínio abdutivo, formação e

\footnotetext{
${ }^{19}$ Por exemplo, durante o estudo dos debates sobre resíduos domésticos na Alemanha e na França realizado por Keller (1998), tornou-se visível apenas de forma gradual, com base na análise do material, o fato de que no debate público sobre resíduos na França havia um único discurso, e outro apenas fora da mídia de massa, enquanto que na discussão alemã dois discursos competiam publicamente na mídia. Para análises adicionais, cf. Keller, Hornidge \& Schünemann (2018).
} 
KELLER, R. - Sobre a práxis da Análise do Discurso da Sociologia do Conhecimento

avaliação de hipóteses. É por isso que o procedimento pode ser esclarecido usando trechos individuais de dados, mas no geral é difícil evitar que os exemplos de dados na apresentação dos resultados sejam ilustrativos. Em última análise, a credibilidade e a sinceridade de pesquisadores e pesquisadoras, transmitidas com mais ou menos sucesso influenciarão a recepção de uma investigação. No entanto, esses não são problemas especiais da pesquisa do discurso.

\section{Considerações finais}

Finalmente, devem ser elencados alguns desiderata do desenvolvimento atual da pesquisa do discurso da sociologia do conhecimento:

- As Análises do Discurso como um todo e também aquelas dentro da estrutura da ADSC têm sido, até agora, fortemente orientadas pelos textos e casos. Existem tentativas de relacionar pesquisas anteriores entre si e de integrar os resultados em um nível mais geral usando a teoria do discurso. Até agora, as visualizações foram consideradas apenas ocasionalmente (por exemplo por BRUNNER 2010, ou FEGTER 2012). Na minha opinião, isso levanta três questões muito diferentes. Por um lado, uma metodologia de análise de visualizações teria que ser desenvolvida para além da metodologia atual de análise qualitativa de imagens individuais, que leve em consideração a incorporação discursiva de fotografias, imagens, gráficos, outras imagens e seu conteúdo enunciativo em seu contexto discursivo. Um segundo ponto de partida pode ser direcionado para a análise dos deslocamentos texto-imagem que Karin Knorr Cetina (2001) trouxe com o conceito de "viscurso" ["Viskurse"]. Isso indica a observação de que, por exemplo, em alguns discursos científicos as estratégias de imagem estão cada vez mais tomando o lugar de representações baseadas em texto. Por fim, as visualizações tornam-se assunto de conflitos discursivos - a pesquisa do discurso, então, não tem que decidir qual seria a interpretação correta da imagem, mas pode se concentrar nos processos sociais envolvidos na produção de mudanças dos significados da imagem (cf. KELLER 2016b, SCHWARZ 2016).

- No contexto da ADSC, há muito tempo proponho um uso mais enérgico do conceito de dispositivo. Com isto, seguindo Foucault e o uso corrente em francês do conceito de dispositivo, entendo (como já explicado acima) duas coisas: de um 
KELLER, R. - Sobre a práxis da Análise do Discurso da Sociologia do Conhecimento

lado, as infraestruturas de produção do discurso; de outro, infraestruturas de intervenção discursiva no mundo. Os dispositivos como infraestruturas para a produção do discurso incluem, por exemplo, recursos de todo tipo (pessoal, instalações, objetos, recursos financeiros, por exemplo, cátedras universitárias e financiamento de pesquisas) que possibilitam as produções específicas de enunciados. Uma vez que os discursos são frequentemente "orientados ao problema", ou seja, querem definir um problema cognitivo ou um problema social (ou negar sua existência), eles geram meios de intervenção no mundo (como bolsas de estudo, formulários de teste para escolas, conceitos de aprendizagem, materiais de ensino, treinamentos, arquiteturas de sala de aula e mobiliário etc) que são usados em campos de ação social e produzem efeitos (nem sempre os desejados). Nesse sentido, os dispositivos formam um entrelaçamento de textos, práticas, atores e artefatos. Seu processamento pode ser examinado mais especificamente no contexto das etnografias com foco no discurso. Com isso é definido um trabalho etnográfico que se concentra especificamente na observação da prática discursiva e dos efeitos dispositivos. $\mathrm{O}$ foco, portanto, se dirige não para um campo específico de atividade, uma área, uma organização ou formação cultural em sua totalidade, mas sim para a observação e a análise de questões da pesquisa do discurso e de dispositivos, ou seja, não apenas para a materialidade simbólica da prática discursiva (cf. KELLER 2005, 2019a, 2019b). ${ }^{20}$

\section{Referências Bibliográficas}

ANGERMÜLLER, Johannes. Sozialwissenschaftliche Diskursanalyse in Deutschland: Zwischen Rekonstruktion und Dekonstruktion. In: KELLER, Reiner; HIRSELAND, Andreas; SCHNEIDER, Werner; VIEHÖVER, Willy (Hrsg.). Die diskursive Konstruktion von Wirklichkeit. Konstanz: UVK, 2005, 23-48.

BERGER, Peter L.; LuCKMANN, Thomas. Die gesellschaftliche Konstruktion der Wirklichkeit: Eine Theorie der Wissenssoziologie. Frankfurt/Main: Fischer, 1980 [1966].

Bowker, Geoffrey C.; STAR, Susan Leigh. Sorting things out: Classification and its consequences. Cambridge: University Press, 2000.

BRUNNER, Claudia. Wissensobjekt Selbstmordattentat: Epistemische Gewalt und okzidentalistische Selbstvergewisserung in der Terrorismusforschung. Wiesbaden: VSVerlag, 2010.

\footnotetext{
${ }^{20}$ Cf. também a edição especial da revista Zeitschrift für Diskursforschung dedicada à etnografia do discurso (ELLIKER; WUNDRAK \& MAEDER 2017) ou, por exemplo, Hornidge; Feuer (2018), bem como no que diz respeito à pesquisa sobre a mentalidade governamental.
} 
KELLER, R. - Sobre a práxis da Análise do Discurso da Sociologia do Conhecimento

Clarke, Adele. Situational Analysis: Grounded Theory after the Postmodern Turn. London: Sage, 2005.

ClARKE, Adele. Situationsanalyse. Wiesbaden: VS-Verlag, 2012 [2005].

DREYFUS, Hubert L.; RABINOW, Paul. Michel Foucault: Jenseits von Strukturalismus und Hermeneutik. Frankfurt a. M.: athenäum, 1987.

EDER, Franz (Hrsg.). Historische Diskursanalysen: Genealogie, Theorie, Anwendungen. Wiesbaden: VS-Verlag, 2006.

ELLIKER, Florian; WUNDRAK, Rixta; MAEDER, Christoph. Introduction to the thematic issue and programmatic thoughts on the Sociology of Knowledge Approach to Discourse Ethnography. Journal for Discourse Studies, v. 3, 232-248, 2017.

FARGe, Arlette; Foucault, Michel. Familiäre Konflikte: Die ,lettres de cachet'. Aus den Archiven der Bastille im 18. Jahrhundert. Frankfurt a. M.: Suhrkamp, 1989.

FEGTER, Susanne. Die Krise der Jungen in Bildung und Erziehung. Diskursive Konstruktion von Geschlecht und Männlichkeit. Wiesbaden: VS Verlag, 2012.

FouCAUlt, Michel (Pseudonym: M. Florence). Aesthetics, Method, and Epistemology: Essential Works of Foucault 1954-1984. New York: The New Press, 2000 [1984], 459-464. v. 2.

Foucault, Michel. Antwort auf eine Frage. In: FouCAult, Michel. Schriften in vier Bänden. Dits et Écrits. Frankfurt a. M.: Suhrkamp, 2001a [1969], 859-886.

Foucault, Michel. Die Ordnung des Diskurses. München: Hanser, 1974 [1972].

Foucault, Michel. Schriften in vier Bänden. Dits et Écrits. Frankfurt a. M.: Suhrkamp, 2001. Bd. 1: 1954-1969.

Foucault, Michel. The Subject and Power. In: DreYfus, H. L.; RABINOW, P. Michel Foucault: Beyond Structuralism and Hermeneutics. 2nd Ed. Chicago: The University of Chicago Press, 1983, 208-228.

Glasze, Georg; MATTISSEK, Anika (Hrsg.). Handbuch Diskurs und Raum. Bielefeld: transcript, 2009.

HABERMAS, Rebekka; MinKMAR, Nils (Hrsg.). Das Schwein des Häuptlings. Sechs Aufsätze zur Historischen Anthropologie. Berlin: Wagenbach, 1992.

HaLl, Stuart. The Centrality of Culture: Notes on the Cultural Revolutions of our Time. In: ThOMPSON, K.; OPEn UnIVERSITY (ed.). Media and Cultural Regulation. London: Sage and The Open University Press, 1997, 207-238.

HITZLER, Ronald; HONER, Anne (Hrsg.). Sozialwissenschaftliche Hermeneutik. Eine Einführung. Opladen: Leske \& Budrich, 1997a.

HITZLER, Ronald; HoNER, Anne. Einleitung: Hermeneutik in der deutschsprachigen Soziologie heute. In: HiTZlER, Ronald; HONER, Anne (Hrsg.). Sozialwissenschaftliche Hermeneutik. Eine Einführung. Opladen: Leske \& Budrich, 1997b, 7-27.

HITZLER, Ronald; ReICHERTZ, Jo; SCHRÖER, Norbert (Hrsg.). Das Arbeitsfeld einer hermeneutischen Wissenssoziologie. In: HITZLER, Ronald; REICHERTZ, Jo; SCHRÖER, Norbert (Hrsg.). Hermeneutische Wissenssoziologie. Standpunkte zur Theorie der Interpretation. Konstanz: UVK, 1999b, 9-13.

HitzleR, Ronald; REICHERTZ, Jo; SCHRÖER, Norbert (Hrsg.). Hermeneutische Wissenssoziologie. Standpunkte zur Theorie der Interpretation. Konstanz: UVK, 1999a.

HORNIDGE, Anna-Katharina; FEUER, Hart Nadav. A SKAD ethnography of educational knowledge discourses. In: KELLER, Reiner; HORNIDGE, Anna-Katharina; SCHÜNEMANN, Wolf (ed.) The sociology of knowledge approach to discourse. Investigating the politics of knowledge and meaning-making. London: Routledge, 2018, 133-149.

JÄGER, Siegfried. Kritische Diskursanalyse. Eine Einführung. 2. überarb. u. erw. Aufl. DISSStudien: Duisburg, 1999 [1993].

KELLER, Reiner. Das Interpretative Paradigma. Wiesbaden: VS-Verlag, 2012.

Pandaemonium, São Paulo, v. 24, n. 44, set.-dez. 2021, p. 475-518 
KELLER, R. - Sobre a práxis da Análise do Discurso da Sociologia do Conhecimento

KELLER, Reiner. Das Wissen der Wörter und Diskurse. Über Sprache und Wissen in der Wissenssoziologischen Diskursanalyse. In: VIEHÖVER, Willy; KELLER, Reiner; SCHNEIDER, Werner (Hrsg.). Diskurs - Sprache - Wissen. Interdisziplinäre Beiträge zum Verhältnis von Sprache und Wissen in der Diskursforschung. Wiesbaden: Springer VS, 2013, 21-49.

KELLER, Reiner. Der menschliche Faktor. In: KELLER, Reiner; SCHNEIDER, Werner; VIEHÖVER, Willy (Hrsg.). Diskurs Macht Subjekt. Theorie und Empirie der Subjektivierung in der Diskursforschung. Wiesbaden: VS-Verlag, 2012, 67-106.

KELLER, Reiner. Die komplexe Diskursivität der Visualisierungen. In: BOSANČIĆ, Saša; KELLER, Reiner (Hrsg.). Perspektiven wissenssoziologischer Diskursforschung. Wiesbaden: Springer VS, 2016b, 75-94.

KELLER, Reiner. Diskursforschung. Eine Einführung für SozialwissenschaftlerInnen. Opladen: Leske \& Budrich, 2003a.

KELLER, Reiner. Doing discourse research: An introduction for social scientists. London \& Thousand Oaks, CA: Sage, 2013 [2003].

KELLER, Reiner. Has Critique Run Out of Steam? On Discourse Research as Critical Inquiry. Qualitative Inquiry, v. 22, n. 6, 1-11, 2016.

KELLER, Reiner. Michel Foucault. Konstanz: UVK, 2008.

KELLER, Reiner. Müll - Die gesellschaftliche Konstruktion des Wertvollen. Opladen: Westdeutscher Verlag, 1998.

KELLER, Reiner. Nach der Gouvernementalitätsforschung und jenseits des Poststrukturalismus? Anmerkungen aus Sicht der Wissenssoziologischen Diskursanalyse. In: ANGERMÜLLER, Johannes; VAN DYK, Silke (Hrsg.). Diskursanalyse meets Gouvernementalitätsforschung: Perspektiven auf das Verhältnis von Subjekt, Sprache, Macht und Wissen. Frankfurt am Main: Campus, 2010, 43-70.

KELLER, Reiner. The sociology of knowledge approach to discourse (SKAD). Human Studies, v. 34, n. 1, 43-65, 2011.

KELLER, Reiner. The Sociology of Knowledge Approach to Discourse. Outline of a Research Program. New York: Springer, 2019.

KELLER, Reiner. Wissen oder Sprache? Für eine wissensanalytische Profilierung der Diskursforschung. In: EDER, Franz (Hrsg.). Historische Diskursanalysen: Genealogie, Theorie, Anwendungen. Wiesbaden: VS-Verlag, 2006, 51-70.

KELLER, Reiner. Wissenssoziologische Diskursanalyse als interpretative Analytik. In: KELLER, Reiner; HIRSElAND, Andreas; SCHNEIDER, Werner; VIEHÖVER, Willy (Hrsg.). Die diskursive Konstruktion von Wirklichkeit. Konstanz: UVK, 2005b, 49-76.

KELLER, Reiner. Wissenssoziologische Diskursanalyse. Grundlegung eines Forschungsprogramms. Wiesbaden: VS-Verlag, 2005a.

KELLER, Reiner. Wissenssoziologische Diskursanalyse. In: Keller, Reiner; HIRSELAND, Andreas; SCHNEIDER, Werner; VIEHÖVER, Willy (Hrsg.). Handbuch Sozialwissenschaftliche Diskursanalyse. Opladen: Leske \& Budrich, 2001, 113-145. Bd. 1: Theorien und Methoden.

KELLER, Reiner. Zum möglichen Verhältnis zwischen Diskursanalyse und Ethnographie. In: Vortrag auf dem Workshop ,Ethnographie der Arbeit - die Arbeit der Ethnographie'. Berlin, 2003b.

Keller, Reiner; HiRSElAND, Andreas; SchneIDER, Werner; VIEHÖVER, Willy (Hrsg.). Handbuch Sozialwissenschaftliche Diskursanalyse. Opladen: Leske \& Budrich, 2001. Bd. 1: Theorien und Methoden.

Keller, Reiner; HiRSElAND, Andreas; SchneIDER, Werner; VIEHÖVER, Willy (Hrsg.). Die diskursive Konstruktion von Wirklichkeit. Zum Verhältnis von Wissenssoziologie und Diskursforschung. Konstanz: UVK, 2005.

Pandaemonium, São Paulo, v. 24, n. 44, set.-dez. 2021, p. 475-518 
KELLER, R. - Sobre a práxis da Análise do Discurso da Sociologia do Conhecimento

KELLER, Reiner; Hornidge, Anna-Katharina \& Schünemann, Wolf (ed.). The sociology of knowledge approach to discourse. Investigating the politics of knowledge and meaningmaking. London: Routledge, 2018.

KelleR, Reiner; KNOBlaUCH, Hubert; ReICHERTZ, Jo (Hrsg.). Kommunikative Konstruktion. Wiesbaden: VS-Verlag, 2012.

KELLER, Reiner; SCHNEIDER, Werner; VIEHÖVER, Willy (Hrsg.). Diskurs Macht Subjekt. Theorie und Empirie der Subjektivierung in der Diskursforschung. Wiesbaden: VS-Verlag, 2012.

KelLER, Reiner; TRUSCHKAT, Inga. Angelus Novus: Über alte und neue Wirklichkeiten der deutschen Universitäten. Sequenzanalyse und Deutungsmusterrekonstruktion in der Wissenssoziologischen Diskursanalyse. In: ANGERMULLER, Johannes; NONHOFF, Martin; HERSCHINGER, Eva; MACGILCHRIST, Felicitas; REISIGL, Martin; WedL, Juliette; WrANA, Daniel; ZIEM, Alexander (Hrsg.). Diskursforschung. Ein interdisziplinäres Handbuch. Bielefeld: transkript, 2014, 294-328. Bd. 2.

KnORR CetinA, Karin. 'Viskurse' der Physik. Konsensbildung und visuelle Darstellung. In: HeInTZ, Bettina; HuBER, Jörg (Hrsg.). Mit dem Auge denken. Strategien der Sichtbarmachung in wissenschaftlichen und virtuellen Welten. Zürich: Edition Voldemeer, 2001, 305-320.

LEIPOLD, Sina. Creating forests with words - A review of forest-related discourse studies. Forest Policy and Economics, v. 40, 12-20, 2014.

MANNHEIM, Karl. Ideologie und Utopie. Frankfurt/Main: Schulte-Bulmke, 1969 [1929].

MEUSER, Michael; SACKMANN, Reinhold (Hrsg.). Analysen sozialer Deutungsmuster. Beiträge zur empirischen Wissenssoziologie. Pfaffenweiler: Centaurus, 1992.

POFERL, Angelika. Kosmopolitik des Alltags. Die ökologische Frage als Handlungsproblem. Berlin: Sigma, 2004.

Ricoeur, Paul. Freud and Philosophy: An Essay on Interpretation. New Haven: Yale University Press, 1970.

SAHLINS, Marshall. Die erneute Wiederkehr des Ereignisses: Zu den Anfängen des Großen Fidschikrieges zwischen den Königreichen Bau und Rewa 1843-1855. In: HABERMAS, Rebekka; Minkmar, Nils (Hrsg.). Das Schwein des Häuptlings. Sechs Aufsätze zur Historischen Anthropologie. Berlin: Wagenbach, 1992a, 84-129.

SCHRÖER, Norbert (Hrsg.). Interpretative Sozialforschung. Auf dem Wege zu einer hermeneutischen Wissenssoziologie. Opladen: Westdeutscher Verlag, 1994.

SCHÜTZE, Yvonne. Das Deutungsmuster ,Mutterliebe' im historischen Wandel. In: MEUSER, Michael; SACKMANN, Reinhold (Hrsg.). Analysen sozialer Deutungsmuster. Beiträge zur empirischen Wissenssoziologie. Pfaffenweiler: Centaurus, 1992, 39-48.

SCHWARZ, Natalie. Die Total-Kontroverse oder das Scheitern eines Rassismus-Diskurses. In: Keller, R.; Raab, J. (ed.). Wissensforschung - Forschungswissen. Weinheim: BeltzJuventa, 2016, 94-105.

SOEFFNER, Hans-Georg. Auslegung des Alltags - Der Alltag der Auslegung: Zur wissenssoziologischen Konzeption einer sozialwissenschaftlichen Hermeneutik. Konstanz: UVK/UTB, 2004, 61-77.

SOEFFNER, Hans-Georg. Verstehende Soziologie und sozialwissenschaftliche Hermeneutik. Die Rekonstruktion der gesellschaftlichen Konstruktion der Lebenswelt. In: HITZLER, Ronald; REICHERTZ, Jo; SCHRÖER, Norbert (Hrsg.). Hermeneutische Wissenssoziologie. Standpunkte zur Theorie der Interpretation. Konstanz: UVK, 1999a [1991], 39-50.

SOEFFNER, Hans-Georg; HITZLER, Ronald. Hermeneutik als Haltung und Handlung. Über methodisch kontrolliertes Verstehen. In: SCHRÖER, Norbert (Hrsg.). Interpretative Sozialforschung. Auf dem Wege zu einer hermeneutischen Wissenssoziologie. Opladen: Westdeutscher Verlag, 1994, 28-55.

STRAUSS, Anselm. Grundlagen qualitativer Sozialforschung. München: UTB, 1998.

Pandaemonium, São Paulo, v. 24, n. 44, set.-dez. 2021, p. 475-518 
KELLER, R. - Sobre a práxis da Análise do Discurso da Sociologia do Conhecimento

ULRICH, Peter; KELLER, Reiner. Comparing Discourse Between Cultures. A Discursive Approach to Movement Knowledge. In: Baumgarten, B.; DAPHI, P.; Ulrich, P. (Hrsg.). Conceptualizing Culture in Social Movement Research. Hampshire: Palgrave, 2014, 113139.

VIEHÖVER, Willy. Diskurse als Narrationen. In: KELLER, Reiner; HIRSELAND, Andreas; SCHNEIDER, Werner; VIEHÖVER, Willy (Hrsg.). Handbuch Sozialwissenschaftliche Diskursanalyse. Opladen: Leske \& Budrich, 2001, 177-206.

Recebido em 12 de abril de 2021 Aceito em 16 de junho de 2021 